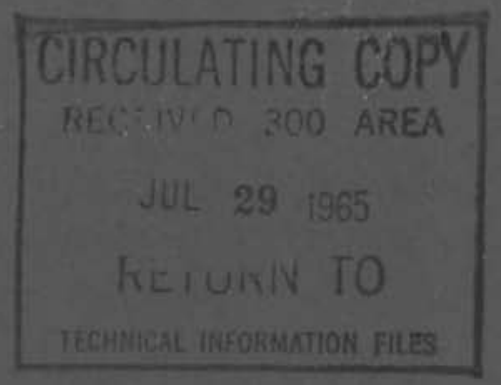

BNWL-95

AEC

\section{BESEARCH}

and

DEVELOPMENT

REPORT

\title{
PHYSICS RESEARCH QUARTERLY REPORT JANUARY, FEBRUARY, MARCH, 1965
}




\section{LEGAL NOTICE}

This report was prepared as an account of Government sponsored work. Neither the United States, nor the Commission, nor ony person acting on beholf of the Commission:

A. Makes any warranty or representation, expressed or implied, with respect to the accurocy, complefeness, or usefulness of the information contained in this report, or that the use of any informotion, apparatus; method, or process disclosed in this report may not infringe privately owned rights; or

B. Assumes any liabilities with respect to the use of, or for domages resulting from the use of any information, apparatus, method, or process disclosed in this report.

As used in the above, "person acting on behalf of the Commission" includes any employee or contractor of the Commission, or employee of such contractor, to the extent that such employee or can. tractor of the Commission, or employee of such contractor prepares, disseminates, or provides access to, any information pursuant to his employment or controct with the Commission, or his employment with such contracior.

\section{PACIFIC NORTHWEST LABORATORY}

RICHLAND, WASHINGTON

operated by

BATTELE MEMORIAL INSTITUTE

for the

UNITED STATES ATOMIC ENERGY COMMISSION UNDER CONTRACT AT(45-1)-1830 


\section{PHYSICS RESEARCH QUARTERLY REPORT}

JANUARY, FEBRUARY, MARCH, 1965

By

The Staffs of

Reactor Physics,

Experimental Physics Research and

Critical Mass Physics

F, G. Dawson, Jr.

C. W. Lindenmeier

F. G. Dawson

P. L. Hofmann

H. L. Henry

R. E. Heineman

B. R. Leonard, Jr.

E. D. Clayton
Manager

Reactor Physics

Manager

Theoretical Physics

Acting Manager

Reactor Analysis

Manager

Engineering Physics

Manager

Experimental Reactors

Manager

Reactor Lattice Physics

Manager

Experimental Physics Research

Manager

Critical Mass Physics

Physics and Instruments Department 
Printed in USA. Price \$3.00. Available from the Clearinghouse for Federal Scientific and Technical Information National Bureau of Standards

U. S. Department of Commerce Springfield, Virginia 


\section{TABLE OF CONTENTS}

$\underline{\text { Page }}$

REACTOR ANALYSIS

Comparison of Measured and Calculated Spectra and Average

Reaction Rates - R. A. Harris, W. A. Reardon

ENGINEERING PHYSICS

Comparison of Diffusion and Transport Calculations for

NPR Tube-in-Tube Fuel Geometry - C. L. Bennett

REACTOR LATTICE PHYSICS

Determination of $\mathrm{k}_{\mathrm{O}}$ for a $\mathrm{PuO}_{2}-\mathrm{UO}_{2}$ Graphite Lattice T. B. Thornbury, N. A. Hill

CRITICAL MASS PHYSICS

Critical Experiments with $\mathrm{PuO}_{2}$-Polystyrene Compacts $\mathrm{Pu}-240-0.0 \%, \mathrm{H} / \mathrm{Pu}=15-\mathrm{C}$. R. Richey, J. D. White

Prompt Neutron Decay Using Monte Carlo Methods of Analysis - L. L. Carter

Interpretation of Pulsed Neutrons and Reactor Noise Experiments in Reflected Reactors - R. W. Albrecht*

* R. W. Albrecht, Department of Nuclear Engineering, University of Washington, consultant to BNW Plutonium Critical Mass Laboratory. 
PREVIOUS REPORTS IN THIS SERIES

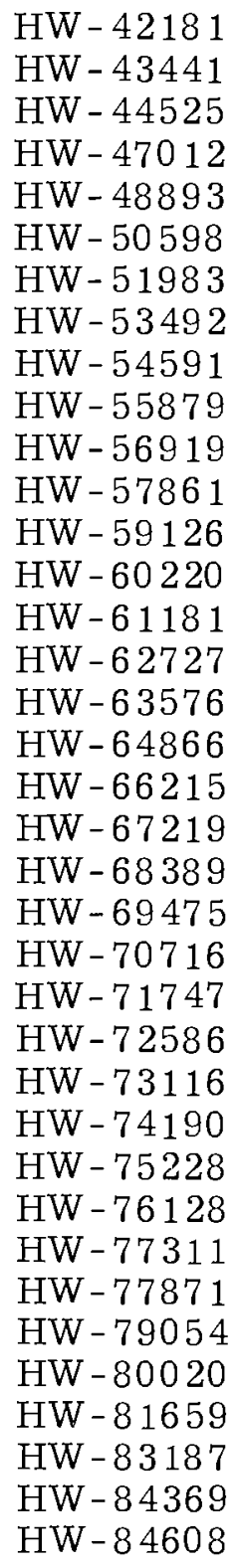

October, November, December

January, February, March

April, May, June

July, August, September

October, November, December

January, February, March

April, May, June

July, August, September

October, November, December

January, February, March

April, May, June

July, August, September

October, November, December

January, February, March

April, May, June

July, August, September

October, November, December

January, February, March

April, May, June

July, August, September

October, November, December

January, February, March

April, May, June

July, August, September

October, November, December

January, February, March

April, May, June

July, August, September

October, November, December

January, February, March

April, May, June

July, August, September

October, November, December

January, February, March

April, May, June

July, August, September

October, November, December
1955

1956

1956

1956

1956

1957

1957

1957

1957

1958

1958

1958

1958

1959

1959

1959

1959

1960

1960

1960

1960

1961

1961

1961

1961

1962

1962

1962

1962

1963

1963

1963

1963

1964

1964

1964

1964 


\title{
REACTOR ANALYSIS
}

Comparison of Measured and Calculated Spectra and Average Reaction Rates

\author{
R. A. Harris, W. A. Reardon
}

\section{INTRODUCTION}

Measured thermal-neutron spectra for several homogeneous, light water and polyethylene moderated systems ${ }^{(1,2)}$ have been compared to spectra calculated by theoretical methods $(3,4)$ presently in use. When plotted as a function of energy, the fluxes produced by these models appear to be similar in shape to those measured. A more realistic measure of the adequacy of the models is to compare average thermal group cross sections. Previously, average cross sections computed with the models were compared to those computed with the model which appeared to yield the most correct spectrum. In this work, average thermal group cross sections (chosen as cross sections for neutrons with energies between 0 and $0.683 \mathrm{eV}$ ) were obtained by integrating energy-dependent cross sections over the measured spectra. These were then compared with the corresponding parameters obtained using the theoretical spectra. To confine the differences observed to those caused by flux shape, all energy dependent cross sections were taken from the same source, the R. B. U. Basic Library, ${ }^{(6)}$ and were assumed to be without error.

(1) J. C. Young, G. D. Trimble, Y. D. Naleboff, D. H. Houston, and J. R. Beyster. "Neutron-Spectrum Measurements in Water, Polyethylene, and Zirconium Hydride, "Nuc. Sci. and Eng., vol. 18, pp. 376-399. 1964.

(2) M. S. Coates, D. H. Day, M. J. Poole, J. C. Smith, and D. J. Tripp. Measurements of Neutron Spectra in Bare Aqueous Plutonium Reactors, AERE R-4668. United Kingdom Atomic Energy Authority. 1964.

(3) J. E. Schlosser. Spectrum V - Infinite Medium Thermal Flux Spectrum Program, HW-71953. General Electric Company, Richland, Washington. December 5, 1961.

(4) R. H. Shudde. NAA Program Description "Tempest - A Neutron Thermalization Code, " North American Aviation Corporation. September 1960.

(5) R. C. Liikala. "Comparison of Thermalization Models, "Physics Research Quarterly Report, January, February, March, 1964, HW-81659. General Electric Company, Richland, Washington (pp. 20-25). April 15, 1964.

(6) R. C. Liikala. Updated R. B. U. Basic Library, HW-75716, vol. 1, vol. 2, and vol. 3. General Electric Company, Richland, Washington. May 20, 1963. 


\section{DESCRIPTION OF EXPERIMENTAL SYSTEMS AND DATA}

\section{A. Nonmultiplying Systems ${ }^{(1)}$}

Thermal spectra were measured for two borated polyethylene systems and for light water solutions containing boron, samarium, and gadolinium. The thermal macroscopic absorption cross section per hydrogen atom (averaged over the measured spectra) for each system was 3. 162, 5. 866, 5.974, 5.536, and 3. 469 barns, respectively. Each system was pulsed with neutrons from a neutron source and time-of-flight techniques were used to obtain the thermal spectra. A complete description of the experiment is included in Reference (1). The tabulated spectral data are for an infinite medium (i. e., a leakage correction was applied to the measured data).

B. Multiplying Systems ${ }^{(2)}$

Thermal spectra for three bare, homogeneous, light water moderated plutonium solutions with $\mathrm{H} / \mathrm{Pu}$ atom ratios of 1197,402 , and 131 were measured. The experimental method used to obtain the spectral data was similar to that described for the nonmultiplying systems. The major exceptions were that no external neutron source was required since the solutions were critical and that the energy of the neutron was determined by a neutron chopper. No leakage correction was applied to the tabulated spectral data to correct it to an infinite medium. Measurements were taken at the center of each core in a region with no flux gradients, and it was therefore assumed that the tabulated spectra closely approximated infinite medium spectra.

\section{CALCULATIONS}

Average thermal group cross sections using both the measured and calculated spectra were calculated by

(1) J. C. Young, G. D. Trimble, Y. D. Naleboff, D. H. Houston, and J. R. Beyster. "Neutron-Spectrum Measurements in Water, Polyethylene, and Zirconium Hydride, "Nuc. Sci. and Eng., vol. 18 pp. 376-399. 1964.

(2) M. S. Coates, D. H. Day, M. J. Poole, J. C. Smith, and D. J. Tripp. Measurements of Neutron Spectra in Bare Aqueous Plutonium Reactors, AERE R-4668. United Kingdom Atomic Energy Authority. 1964. 


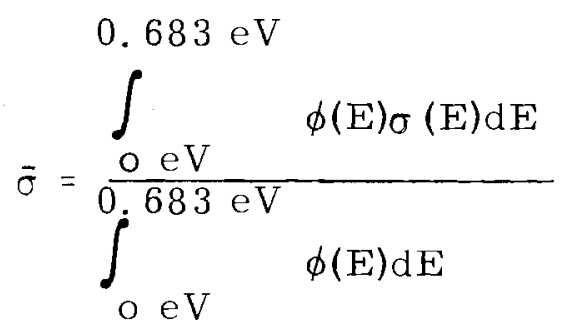

\section{A. Measured Spectra}

A FORTRAN II code (NORM) was written to calculate average thermal group cross sections using the measured spectra. Energy dependent cross sections for the materials in each of the systems were obtained from the R. B. U. Basic Library ${ }^{(1)}$ using the BARNS II ${ }^{(2)}$ code.

Two integration schemes were employed in the NORM code. The first utilized trapezoidal integration, the second fitted four data points to a four term polynomial and then integrated analytically between the two middle points. The accuracy of an integration scheme is, of course, dependent upon the energy spacing employed. Since the spectral data for the multiplying systems were obtained at fewer energy points than the nonmultiplying systems, the two integration methods were compared using the energy meshes of the plutonium solutions. The value of a Maxwollian flux was obtained for each point in an energy mesh and then these values were integrated from 0 to $0.1 \mathrm{eV}$. A comparison with the analytical integral showed maximum errors of $0.5 \%$ and $0.01 \%$ (both occurring with $\mathrm{H} / \mathrm{Pu}=131$ energy mesh) for the trapezoidal and four term polynomial integration schemes respectively. As may be seen in Table IV (p. 15) an error of $0.01 \%$ is negligible when compared with the differences between average cross sections calculated with spectra obtained from the thermalization models and those calculated from the mcasured data. Therefore, the four term polynomial integration method was chosen for this work. The TEMPEST ${ }^{(3)}$ code integrates using a five term polynomial and, therefore,

(1) R. C. Liikala. Updated R. B. U. Basic Library, HW-75716, vol. 1, vol. 2, vol. 3, General Electric Company, Richland, Washington, May 20, 1963.

(2) J. L. Carter, Private Communication.

(3) R. H. Shudde. NAA Program Description "Tempest - A Neutron Thernalization Code, "North American Aviation Corporation. September, 1960. 
is consistent with the method chosen for the calculations using measured data. Since the SPECTRUM ${ }^{(1)}$ code employs trapezoidal integration, average cross sections were computed with the NORM code using the fluxes calculated by the SPECTRUM code.

In each system, the data were extrapolated to zero energy using a Maxwellian distribution of the form $\phi(E)=A E e^{-E / k T}$, where $k T$ is the energy of the peak of the flux curve. The data for the nonmultiplying systems were such that only $\sim 1 \%$ of the total thermal group reaction rate was below the energy of the last data point. It was therefore assumed that any error introduced by the extrapolation method would not significantly affect the average cross sections. In the multiplying systems $\sim 10$ to $15 \%$ of the total thermal group reaction rate occurred in the extrapolated flux. To test the sensitivity of the extrapolation method, average thermal group cross sections were computed for two limiting cases; $k T=1000 \mathrm{eV}$ $(\phi \cong \mathrm{A} \cdot \mathrm{E})$ and $\mathrm{kT}=0.0253 \mathrm{eV}$ (no absorption). The results are tabulated in Table I.

TABLE I

SENSITIVITY OF EXTRAPOLATION METHOD

\begin{tabular}{|c|c|c|c|c|c|}
\hline \multirow[b]{3}{*}{$\underline{\mathrm{H}} / \mathrm{Pu}$} & \multirow[b]{3}{*}{ kT(Data)eV } & \multicolumn{4}{|c|}{$\begin{array}{l}\text { Percent Differences from } \bar{\sigma}_{a} \\
\text { Calculated with kT(Data) }\end{array}$} \\
\hline & & $\mathrm{k}^{\prime}$ & $00 \mathrm{eV}$ & $\mathrm{kT}=0$ & $3 \mathrm{eV}$ \\
\hline & & $\overline{\bar{\sigma}}_{\mathrm{a}(1 / \mathrm{v})}$ & $\bar{\sigma}_{\mathrm{a} \mathrm{Pu}}{ }^{239}$ & $\bar{\sigma}_{a(1 / v)}$ & $\overline{\bar{\sigma}}_{\mathrm{a} \mathrm{Pu}}{ }^{239}$ \\
\hline 1197 & 0.028 & -1.72 & -1.07 & +0.21 & +0.13 \\
\hline 402 & 0.030 & -1.94 & -0.92 & +0.43 & +0.20 \\
\hline 131 & 0.045 & -2.13 & -0.67 & +2.14 & +0.68 \\
\hline
\end{tabular}

Since the differences in Table I are for the limits of the extrapolated flux, the actual error in average cross sections would be considerably less than these differences and therefore not expected to affect the results of this study.

(1) J. E. Schlosser. Spectrum V - Infinite Medium Thermal Flux Spectrum Program, HW-71953. General Electric Company, Richland, Washington. December 5, 1961. 
The magnitude of the error in a cross section averaged over a measured spectrum due to the experimental error was evaluated using the data for the $\mathrm{H} / \mathrm{Pu}=131$ system. The experimental error assigned to the tabulated data is $\sim \pm 5 \%$. $(1,2)$ It was assumed that the error in each of the flux measurements was independent of that in any other flux measurement since the experimental error was primarily attributed to statistical effects. The error in total reaction rate for the $\mathrm{H} / \mathrm{Pu}=131$ system would then be $\sim \pm 0.96 \%$ and the error in the total flux would be $\sim \pm 0.93 \%$. In calculating the average macroscopic absorption cross section it was assumed that the errors in reaction rate and flux were directly dependent (since the only error is assumed to be in the flux). The resulting error in the average absorption cross section is $\pm 0.03 \%$.

B. Theoretical Models

Spectra using the Nelkin ${ }^{(3)}$ thermalization model were calculated with the SPECTRUM ${ }^{(4)}$ code using scattering kernels generated by the KERNEL ${ }^{(5)}$ code. The TEMPEST code ${ }^{(6)}$ was used to calculate spectra

(1) J. C. Young, G. D. Trimble, Y. D. Naleboff, D. H. Houston, and J. R. Beyster." Neutron-Spectrum Measurements in Water, Polyethylene, and Zirconium Hydride, "Nuc. Sci. and Eng., vol. 18, pp. 376-399. 1964.

(2) M. S. Coates, D. H. Day, M. J. Poole, J. C. Smith, and D. J. Tripp. Measurements of Neutron Spectra in Bare Aqueous Plutonium Reactors, AERE R-4668. United Kingdom Atomic Energy Authority. 1964.

(3) M. Nelkin. "Scattering of Slow Neutrons by Water, "Phys. Rev., vol. 119, pp. 741-746. 1960.

(4) J. E. Schlosser. Spectrum V-Infinite Medium Thermal Flux Spectrum Program, HW-71953, General Electric Company, Richland, Washington. December 5, 1961.

(5) C. W. Lindenmeier, D. D. Matsumoto, and D. R. Skeen. Program Kernel, HW-78288, General Electric Company, Richland, Washington.

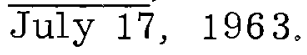

(6) R. H. Shudde. NAA Program Description "Tempest - A Neutron Thermalization Code, "North American Aviation Corporation, September, 1960. 
using the Wigner and Wigner-Wilkins thermalization models. Since the measured spectra for the nonmultiplying systems were corrected to an infinite medium, no leakage effects were included in the calculations using the theoretical models. The data for the multiplying systems were not corrected for leakage; however, the measurements were made so as to approximate an infinite medium (see Section II B). To evaluate the possible effects of leakage, the TEMPEST code was run using an appropriate $\mathrm{B}^{2}$ (buckling) and $\mathrm{B}^{2}=0$ (infinite medium). The largest differences between cross sections thus obtained were quite small $\left[0.06 \%\right.$ for $\bar{\sigma}_{\mathrm{a}}\left(\mathrm{Pu}^{239}\right)$ and $0.1 \%$ for $\left.\bar{\sigma}_{\mathrm{a}}(1 / \mathrm{v})\right]$, and it was concluded that no leakage corrections were needed.

IV. DISCUSSION

The spectra generated with the theoretical models are shown with the measured spectra in Figures 1 - 3. As presented in References (1) and (2), page 8 , the calculated spectra are generally softer than those measured.

\section{A. Nonmultiplying Systems}

The spectra of the $1 / \mathrm{v}$ poisoned systems were originally measured to obtain spectra which would simulate those from uranium fueled cores since the absorption cross section of $\mathrm{U}^{235}$ behaves very nearly as $1 / \mathrm{v}$. It is apparent from Table II that a considerable range of differences between the values calculated from theoretical spectra and the measured spectra are obtained. Generally the spectrum using the Wigner-Wilkins model produces the poorest values and the spectrum using the Nelkin model the best values. In an uranium system, however, the difference would not be expected to produce drastic effects on reactivity because the capture-to-fission ratio is constant over nearly all the thermal range, and the $1 / \mathrm{v}$ behavior of the absorption cross sections assures, at worst, that there would be nearly cancelling errors in thermal utilization. Liikala ${ }^{(1)}$ has shown that the value

(1) R. C. Liikala. "Compariso n of Thermalization Models, " Physics Research Quarterly Report, January, February, March, 1964 , HW-81659, pp. 20-25, General Electric Company, Richland, Washington. April 15, 1964. 


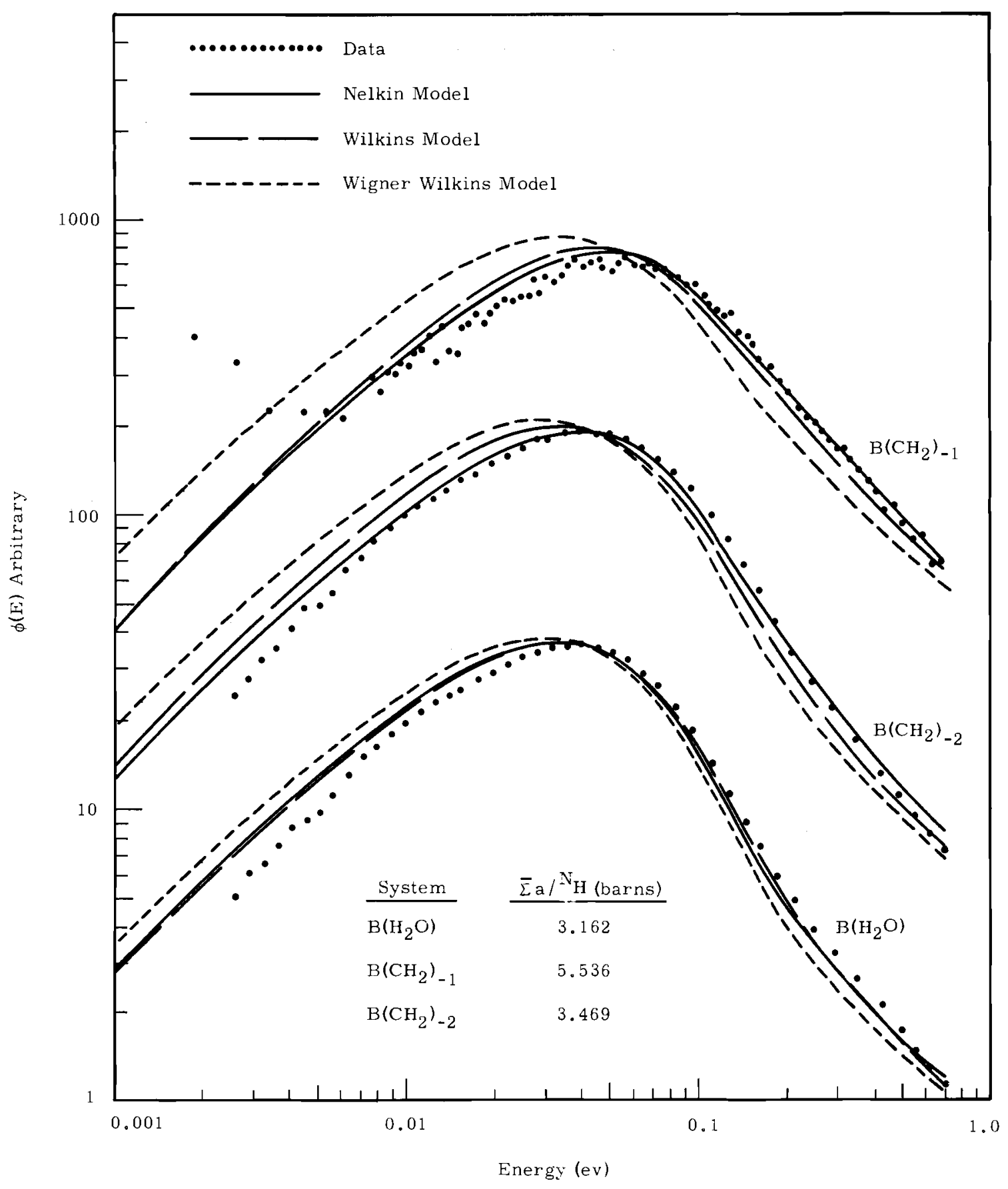

FIGURE 1

Thermal Neutron Spectra

(Spectra are normalized to produce the same reaction rate in a given system.) 


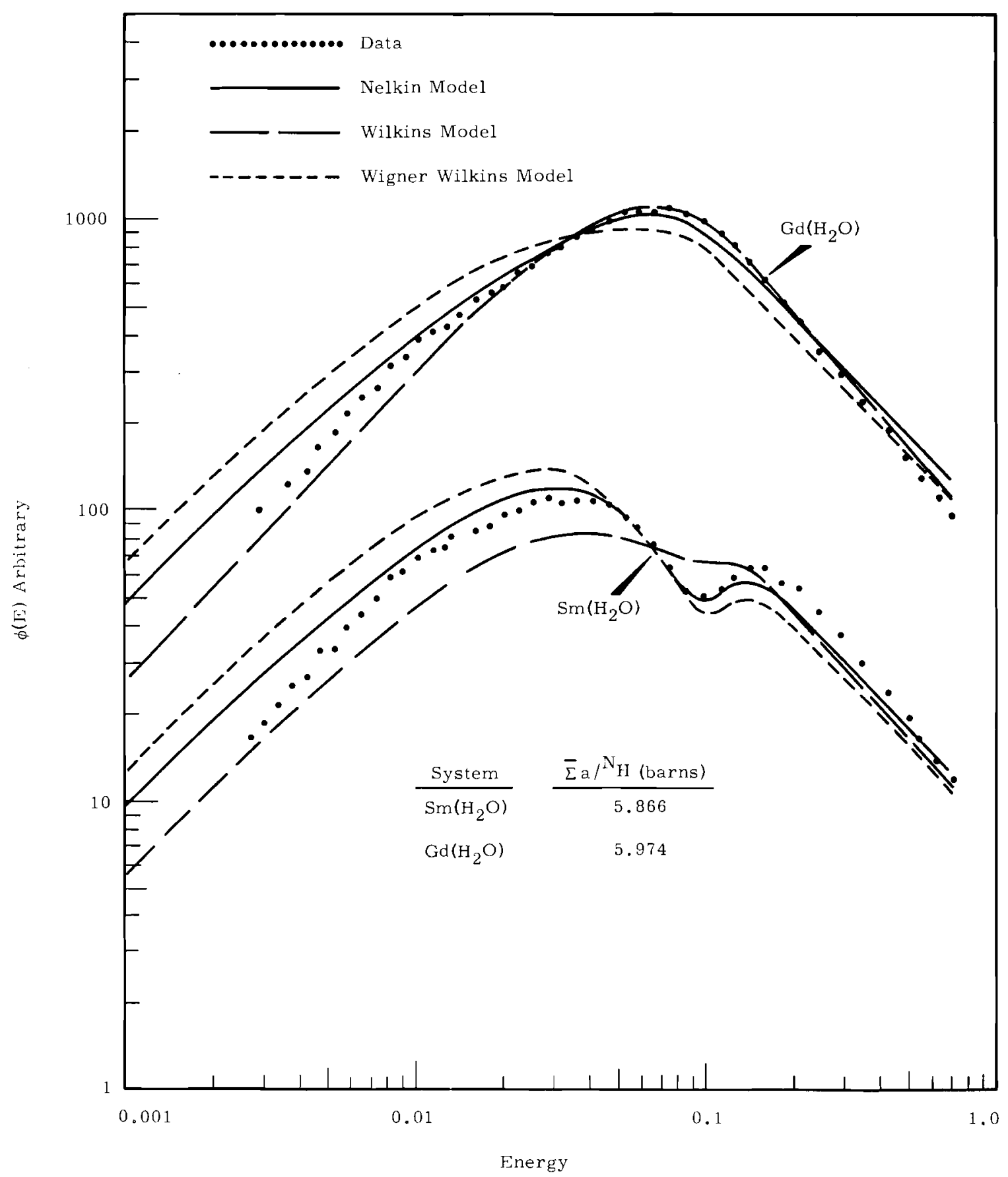

FIGURE 2

Thermal Neutron Spe ctra

(Spectra are normalized to produce the same reaction rate in a given system.) 


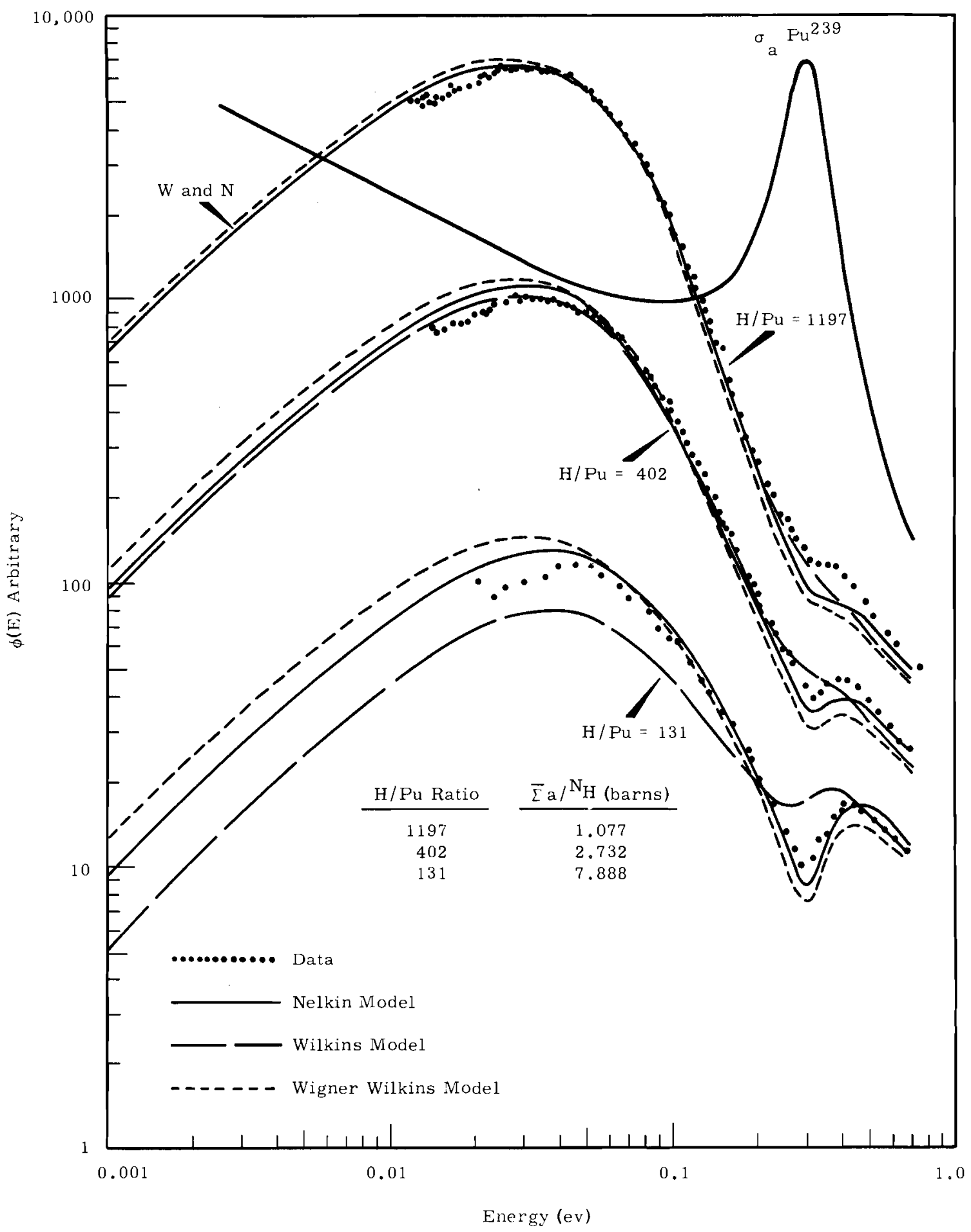

FIGURE 3

Thermal Neutron Spectra

(Spectra are normalized to produce the same reaction rate in a given system.) 
of $\bar{\Sigma}_{\mathrm{f}} / \bar{\Sigma}_{\mathrm{a}}$ (or $\eta \mathrm{f} / \nu$ ) obtained from spectra using all three theoretical models, for a wide range of $\mathrm{H} / \mathrm{U}$ atom ratios, are quite similar.

TABLE II

\section{DIFFERENCES BETWEEN AVERAGE CROSS SECTIONS CALCULATED}

FROM EXPERIMENTAL DATA AND THEORETICAL SPECTRA

\section{FOR NONMULTIPLYING SYSTEMS}

(Cross sections were averaged from 0 to $0.683 \mathrm{eV}$.)

\begin{tabular}{|c|c|c|c|c|c|c|}
\hline \multirow[b]{2}{*}{ System } & \multirow{2}{*}{$\underline{\Sigma} \mathrm{a} / \mathrm{N}_{\mathrm{H}}$} & \multirow[b]{2}{*}{ Material } & \multirow{2}{*}{$\begin{array}{c}\bar{\sigma}_{\text {a from }} \\
\text { Data } \\
\end{array}$} & \multicolumn{3}{|c|}{ Percent Difference for Models } \\
\hline & & & & Nelkin & Wilkins & Wigner-Wilkins \\
\hline \multirow[t]{2}{*}{$\mathrm{B}\left(\mathrm{H}_{2} \mathrm{O}\right)$} & 3. 162 & $\mathrm{~B}$ & 462.28 & +4.93 & +3.97 & +9.78 \\
\hline & & $\mathrm{H}$ & 0.20498 & +4.93 & +3.97 & +9.78 \\
\hline \multirow[t]{2}{*}{$\mathrm{B}\left(\mathrm{CH}_{2}\right)$} & 5.536 & B & 382.81 & -1.08 & +2.18 & +11.92 \\
\hline & & $\mathrm{H}$ & 0.16974 & -1.08 & +2.18 & +11.92 \\
\hline \multirow[t]{2}{*}{$\mathrm{B}\left(\mathrm{CH}_{2}\right)$} & 3.469 & $\mathrm{~B}$ & 437.31 & +0.83 & +6.14 & +12.76 \\
\hline & & $\mathrm{H}$ & 0.19391 & +0.83 & +6.14 & +12.76 \\
\hline \multirow[t]{2}{*}{$\mathrm{Sm}\left(\mathrm{H}_{2} \mathrm{O}\right)$} & 5.866 & $\mathrm{Sm}$ & 3990.3 & +5.89 & +11.65 & +13.29 \\
\hline & & $\mathrm{H}$ & 0.15777 & +5.55 & -2.05 & +14.31 \\
\hline \multirow[t]{2}{*}{$\mathrm{Gd}\left(\mathrm{H}_{2} \mathrm{O}\right)$} & 5.974 & Gd & 13749.0 & -1.62 & -2.89 & +9.98 \\
\hline & & $\mathrm{H}$ & 0.15643 & -1.23 & -1.54 & +3.79 \\
\hline
\end{tabular}

The samarium system spectrum was measured to approximate the spectrum of a plutonium poisoned core. Since systems containing plutonium were actually measured, ${ }^{(1)}$ the samarium data was not evaluated as a plutonium system. By increasing the number of energy groups chosen to cover the thermal range from one to three, the differences in the average cross sections shown in Table II can be reduced to those shown in Table III. Accompanying this reduction is the difficulty encountered in obtaining cross sections for the transfer of neutrons between thermal groups.

(1) M. S. Coates, D. H. Day, M. J. Poole, J. C. Smith, and D. J. Tripp. Measurements of Neutron Spectra in Bare Aqueous Plutonium Reactors, AERE R-4668. United Kingdom Atomic Energy Authority. 1964. 


\section{TABLE III}

\section{DIFFERENCES BETWEEN AVERAGE CROSS SECTIONS CALCULATED}

FROM EXPERIMENTAL DATA AND THEORETICAL SPECTRA FOR A SAMARIUM WATER SOLUTION

(Cross Sections were averaged over three thermal energy groups.)

\begin{tabular}{|c|c|c|c|c|c|}
\hline \multirow[b]{2}{*}{ Energy Interval } & \multirow{2}{*}{\multicolumn{2}{|c|}{$\begin{array}{c}\bar{\sigma}_{\mathrm{a}} \text { from } \\
\text { Data } \\
\end{array}$}} & \multicolumn{3}{|c|}{ Percent Difference for Models } \\
\hline & & & Nelkin & Wilkins & Wigner-Wilkins \\
\hline \multirow[t]{2}{*}{0 to $0.03 \mathrm{eV}$} & $\mathrm{Sm}$ & 6514.5 & +1.20 & +0.41 & +1.86 \\
\hline & $\mathrm{H}$ & 0.42787 & +1.81 & +0.42 & +2.95 \\
\hline \multirow[t]{2}{*}{0.03 to $0.15 \mathrm{eV}$} & $\mathrm{Sm}$ & 9647.5 & +0.0 & +5.25 & -0.95 \\
\hline & $\mathrm{H}$ & 0.19960 & +1.31 & -3.61 & +3.42 \\
\hline \multirow[t]{2}{*}{0.15 to $0.683 \mathrm{eV}$} & $\mathrm{Sm}$ & 548.86 & -2.90 & +4.31 & -2.07 \\
\hline & $\mathrm{H}$ & 0.096628 & -0.96 & +0.28 & -0.88 \\
\hline
\end{tabular}

\section{B. Multiplying Systems}

The average cross sections tabulated in Table IV and the neutron spectra shown in Figure 3 were generated using the cross section data of Leonard ${ }^{(1)}$ for $\mathrm{Pu}^{239}$. Similar calculations employing the data of Sher ${ }^{(2)}$ yielded very similar cross section errors. The neutron spectra calculated by the codes TEMPEST and SPECTRUM were insensitive to the cross section set $^{(1,2)}$ used. It is evident from Table IV that the average absorption cross section of $\mathrm{Pu}^{239}$ is less sensitive to the spectrum employed in obtaining it than the corresponding value for a $1 / \mathrm{v}$ absorber except for the spectrum calculated using the Wilkins model. From Figure 3 it is evident that the calculated fluxes below $0.03 \mathrm{eV}$ are higher than the measured flux for unit reaction rate normalization except for those calculated using the Wilkins model. Similarly, the calculated fluxes are lower than the measured flux in

(1) B. R. Leonard, Jr. "Low Energy Cross Sections of Fissile Nuclides, " Neutron Physics, Proceedings of the Symposium Held at Rensselaer Polytechnic Institute, May 1961 , pp. 3-33. Edited by M. L. Yeater, Academic Press, New York, N.Y. 1962.

(2) R. Sher and J. Felberbaum. Least Squares Analysis for $2200 \mathrm{~m} / \mathrm{sec}$ Parameters of U233, U235, and $\mathrm{Pu} 239, \overline{\mathrm{BNL}}-722$, Brookhaven National Laboratory. June 1962. 
the resonance region. The increased fluxes below $0.03 \mathrm{eV}$ yield higher average cross sections for both $\mathrm{Pu}^{239}$ and a $1 / \mathrm{v}$ absorber. For $\mathrm{Pu}^{239}$ this effect is partially cancelled by the decreased absorption in the resonance region (see shape of $\mathrm{Pu}^{239}$ absorption cross section in Figure 3 ).

TABLE IV

\section{DIFFERENCES BETWEEN AVERAGE CROSS SECTIONS CALCULATED}

FROM EXPERIMENTAL DATA AND THEORETICAL SPECTRA

FOR PLUTONIUM WATER SOLUTIONS

(Cross sections were averaged from 0 to $0.683 \mathrm{eV}$. )

\begin{tabular}{|c|c|c|c|c|c|c|}
\hline \multirow{2}{*}{$\mathrm{H} / \mathrm{Pu}$} & \multirow{2}{*}{$\Sigma_{\mathrm{a}} / \mathrm{N}_{\mathrm{H}}$} & \multirow[b]{2}{*}{ Parameter } & \multirow[b]{2}{*}{ Value Data } & \multicolumn{3}{|c|}{ Percent Difference in Models } \\
\hline & & & & Nelkin & Wilkins & Wigner-Wilkins \\
\hline \multirow[t]{4}{*}{1197} & 1.077 & $\bar{\sigma}_{\mathrm{a}} \mathrm{Pu}{ }^{23}$ & 1017.4 & -0.80 & +0.27 & -0.86 \\
\hline & & $\bar{\sigma}_{\mathrm{a}} \mathrm{H}$ & 0.25901 & +2.86 & +3.10 & +5.20 \\
\hline & & $\vec{\sigma}_{\mathrm{f}} / \bar{\sigma}_{\mathrm{a}}\left(\mathrm{Pu}^{239}\right)$ & 0.70579 & +0.68 & +0.54 & +1.15 \\
\hline & & $\bar{\Sigma}_{\mathrm{f}} / \bar{\Sigma}_{\mathrm{a}}$ & 0.52967 & -0.23 & -0.15 & -0.36 \\
\hline \multirow[t]{4}{*}{402} & 2.732 & $\bar{\sigma}_{\mathrm{a}} \mathrm{Pu} 239$ & 1047.6 & -1.33 & +3.78 & -1.45 \\
\hline & & $\bar{\sigma}_{\mathrm{a}} \mathrm{H}$ & 0.22747 & +4.89 & +2.98 & +9.24 \\
\hline & & $\bar{\sigma}_{\mathrm{f}} / \bar{\sigma}_{\mathrm{a}}\left(\mathrm{Pu}{ }^{239}\right)$ & 0.68670 & +1.04 & +0.02 & +1.80 \\
\hline & & $\bar{\Sigma}_{\mathrm{f}} / \bar{\Sigma}_{\mathrm{a}}^{a}$ & 0.62272 & +0.47 & +0.10 & +0.81 \\
\hline \multirow[t]{4}{*}{131} & 7.888 & $\bar{\sigma}_{\mathrm{a}} \mathrm{Pu} 239$ & 1051.9 & -3.93 & +14.84 & -3.47 \\
\hline & & $\bar{\sigma}_{\mathrm{a}} \mathrm{H}$ & 0.18147 & +4.36 & -9.36 & +11.90 \\
\hline & & $\bar{\sigma}_{f} / \bar{\sigma}_{\mathrm{a}}\left(\mathrm{Pu}{ }^{239}\right)$ & 0.66461 & +1.02 & -2.34 & +2.00 \\
\hline & & $\bar{\Sigma}_{\mathrm{f}} / \bar{\Sigma}_{\mathrm{a}}$ & 0.64276 & +0.75 & -1.72 & +1.54 \\
\hline
\end{tabular}

The value of $\alpha\left(\mathrm{Pu}^{239}\right)$ varies considerably in the thermal range, therefore the assumption of cancelling errors in the calculation of the ratio $\bar{\Sigma}_{\mathrm{f}} / \bar{\Sigma}_{\mathrm{a}}$, as assumed for $\mathrm{U}^{235}$ systems, is not correct. The differences for $\bar{\Sigma}_{\mathrm{f}} / \bar{\Sigma}_{\mathrm{a}}$ shown in Table IV are, however, smaller than those calculated for the individual cross sections.

\section{CONCLUSIONS}

Assuming that all systematic errors in the experimental data have been removed, and the remaining errors are the result of counting statistics, 
"jitter" in timing circuits, etc., the calculated total fluxes and reaction rates are accurate to somewhat less than $\pm 1 \%$. Average cross sections will be calculated to an accuracy of $\sim 0.03 \%$, assuming no error in the microscopic cross sections. The extrapolation of the data to zero energy introduces a negligible error. Comparisons have been made between average values of cross sections (and some ratios) obtained by integrating over the measured spectrum and those obtained from spectra calculated assuming either the Nelkin, Wilkins, or Wigner-Wilkins scattering model.

Pertinent observations from these comparisons are:

- In the case of $1 / \mathrm{v}$ poisoned, $\mathrm{H}_{2} \mathrm{O}$ systems, all three computation models yield values of $\bar{\sigma}_{a}$ which are too high by 4 to $10 \%$ (Table II).

- For $1 / \mathrm{v}$ poisoned polyethylene systems the spectra calculated using the Nelking kernel, modified for polyethylene, yield values $\sim 1 \%$ low to $0.8 \%$ high. (The systems were heavily poisoned, see Table II). The spectra calculated with the Wilkins kernel yielded better values than the spectra calculated with the WignerWilkins model, the latter being 12 to $13 \%$ too high and the former 2 to $6 \%$ too high.

- For systems poisoned with materials having low lying resonances (gadolinium and samarium), the spectra obtained with the Nelkin kernel (for $\mathrm{H}$ in $\mathrm{H}_{2} \mathrm{O}$ in this instance) still yield better values for $\bar{\sigma}_{a}$ than the spectra calculated with either the Wilkins or WignerWilkins kernels. The values obtained from spectra calculated with the Nelkin kernel varied from -2 to $+6 \%$, while the other two calculated spectra yielded values varying over a considerably wider range $(-3$ to $+14 \%)$.

- It might be expected that spectra for plutonium systems could be approximated by measuring the spectra of systems containing materials with low lying resonances (i.e., samarium with a resonance of $\sim 0.1 \mathrm{eV})$. A comparison of the cross section values calculated with the spectrum from such a system (Table II) with the values calculated with the spectrum from the plutonium systems (Table IV) indicates that the approximation is not valid. Where $\bar{\sigma}_{\mathrm{a}}(\mathrm{Sm})$ is found to be $\sim 6 \%$ too high, $\bar{\sigma}\left(\mathrm{Pu}^{239}\right)$ is found to be too low by $\sim 3 \%$ for spectra calculated using the Nelkin model and for 
systems with approximately equal values of $\bar{\Sigma}_{a} / N_{H}$. Similar behavior is observed for spectrum obtained from the WignerWilkins model. The spectrum calculated from the Wilkins model, on the other hand, behaves about as would be hoped except that the value of $\bar{\sigma}_{\mathrm{a}}\left(\mathrm{Pu}^{239}\right)$ is $\sim 12 \%$ too high. The possibility of systematic errors between the two types of measurements (pulsed source versus chopper) could certainly exist. Foil data and calculations accompanying the plutonium solution data suggest that the Nelkin kernal and microscopic cross sections in use at Harwell, together yield predictions of reaction rate ratios within the probable errors in the data. It is not within the scope of this study to assess the possible systematic differences between the two types of measurements.

- Finally, it is apparent that spectra obtained from the Nelkin and Wigner-Wilkins kernels will produce average absorption cross sections for plutonium within a range of -1 to $+4 \%$ of tho se that would be obtained from the measured spectra (Table IV). It is also apparent that spectra calculated using the Nelking kernel yield average absorption cross sections for $1 / \mathrm{v}$ absorbers which are a factor of two better than those values obtained from spectra using the Wigner-Wilkins kernel.

Tables II and IV can be used to assess the possible errors which could be expected for the various methods of computation. 


\title{
ENGINEERING PHYSICS
}

\section{Comparison of Diffusion and Transport Calculations for NPR}

\section{Tube-in-Tube Fuel Geometry}

\author{
C. L. Bennett
}

\section{$\underline{\text { INTRODUCTION }}$}

In fuel cycle calculations the use of diffusion theory coupled into an automatic burnup routine is often a great convenience. A series of fuel cycle studies for the NPR were recently carried out $(1,2,3)$ where such a procedure was used. In the NPR unit cell the absorption rate in the fuel region is quite high and, hence, error in the multiplication constant brought about by the use of diffusion theory were expected to be small.

The purpose of the present study is to check this conjecture for a particular NPR fuel geometry and composition. The results show that the use of diffusion theory for NPR fuel cycle survey calculations represents an adequate approach.

\section{SYSTEM}

The system studied is an NPR unit cell in cylindrical geometry with zirconium clad, uranium metal, tube-in-tube fuel (0.947 wt \% U ${ }^{235}$ enriched). The NPR is water cooled and graphite moderated. Two temperature conditions are imposed; "cold" - all cell components at room temperature and "hot" - all components at temperatures typical of Phase III (power only) operation.

(1) G. J. Busselman, E. E. Mills, and C. L. Bennett. Nuclear Characteristics of $\mathrm{UO}_{2}$ and $\mathrm{ThO}_{2}$ Fuel for Phase III NPR Operations, HW-84193, General Electric Company, Richland, Washington. September 22, 1964.

(2) C. L. Bennett and E. E. Mills. Nuclear Characteristics of Uranium Metal Fuel for Phase III NPR Operations, HW-84531, General Electric Company, Richland, Washington. December 1, 1964.

(3) E. E. Mills and C. L. Bennett. Nuclear Characteristics of PuO 2 Fuel for Phase III NPR Operation, HW-84586, General Electric Company, Richland, Washington. December 31, 1964. 


\section{METHODS}

The diffusion calculations were performed with the code HFN, (1) and the transport calculations with $\mathrm{S}-\mathrm{XIII},{ }^{(2)}$ an $\mathrm{S}_{\mathrm{n}}$ code. Four energy groups and identical mesh spacings were employed for both calculations.

For cross section averaging the unit cell is divided into three regions; inner fuel, outer fuel, and graphite. The fuel regions include the clad and adjacent coolant. The thermal spectrum is calculated by the TEMPEST ${ }^{(3)}$ code using the Wilkins heavy moderator approximation. The spectrum above $0.683 \mathrm{eV}$ is treated by the $\operatorname{GAM}^{(4)}$ code using the P-1 slowing down approximation. Three broad epithermal groups are formed by averaging 66 point cross sections over the GAM spectrum. The first broad group contains all of the fission neutrons and extends down to $1.17 \times 10^{4} \mathrm{eV}$. The second group covers the range down to $2.38 \mathrm{eV}$ and the third meets the thermal spectrum at $0.683 \mathrm{eV}$. The microscopic cross sections for each isotope are then rearranged in HFN format by the code SIGMA-3H. ${ }^{(5)}$ The $S_{n}$ cross section format is also formed.

(1) J. R. Lilley. Computer Code HFN - A Multi-Group, Multi-Region Neutron Diffusion Theory in One-Space Dimension, HW-71545, General Electric Company, Richland, Washington. October, 1961.

(2) B. H. Duane. Neutron and Photon Transport, Plane-Cylinder-Sphere, GE-ANPD Program S, Variational Optimum Formulation, XDC 59-9-118 General Electric Aircraft Nuclear Propulsion Department. 1959.

(3) R. R. Shudde and J. Dyer, NAA Program Description. TEMPEST, A Neutron Thermalization Code. September, 1960.

(4) G. D. Joanou and J. S. Dudek. GAM-1, A Consistent P 1 Multi-Group Code for the Calculation of Fast Neutron Spectra and Multi-Group Constants, GA-1850, General Atomic Division, General Dynamics Corporation. June, 1961.

(5) E. L. Kelley, Jr. User's Manual for HFN and Calx Chain, HW-80968, General Electric Company, Richland, Washington. March 16, 1964. 


\section{RESULTS AND DISCUSSION}

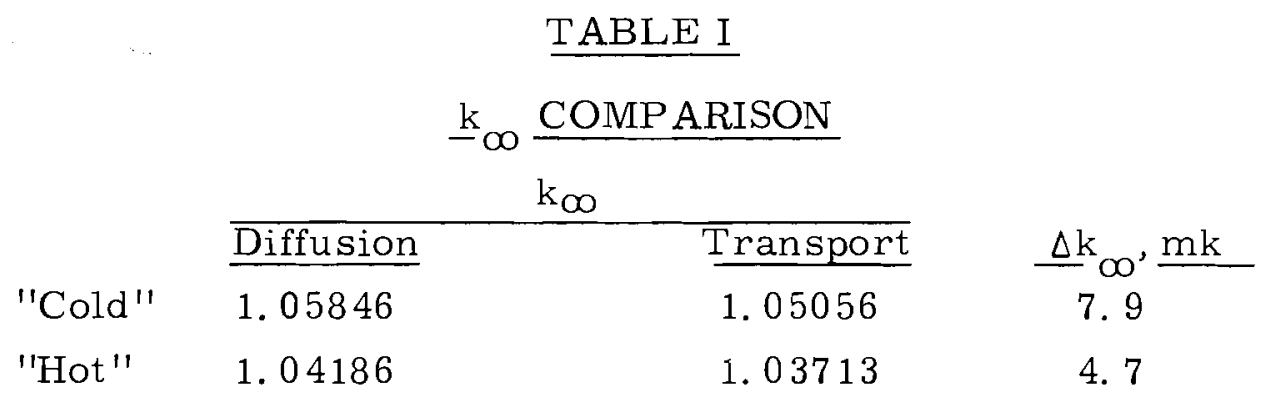

The comparison of $\mathrm{k}_{\infty}$ 's obtained by the two methods is quite good as can be seen in Table I above. The difference in $\mathrm{k}_{\infty}$ can be attributed mainly to the change in the thermal utilization brought about by the differences in the thermal flux depression in the fuel. (See Figures 1 and 2, and Table II.) The thermal flux depression factors in the "cold" case, obtained

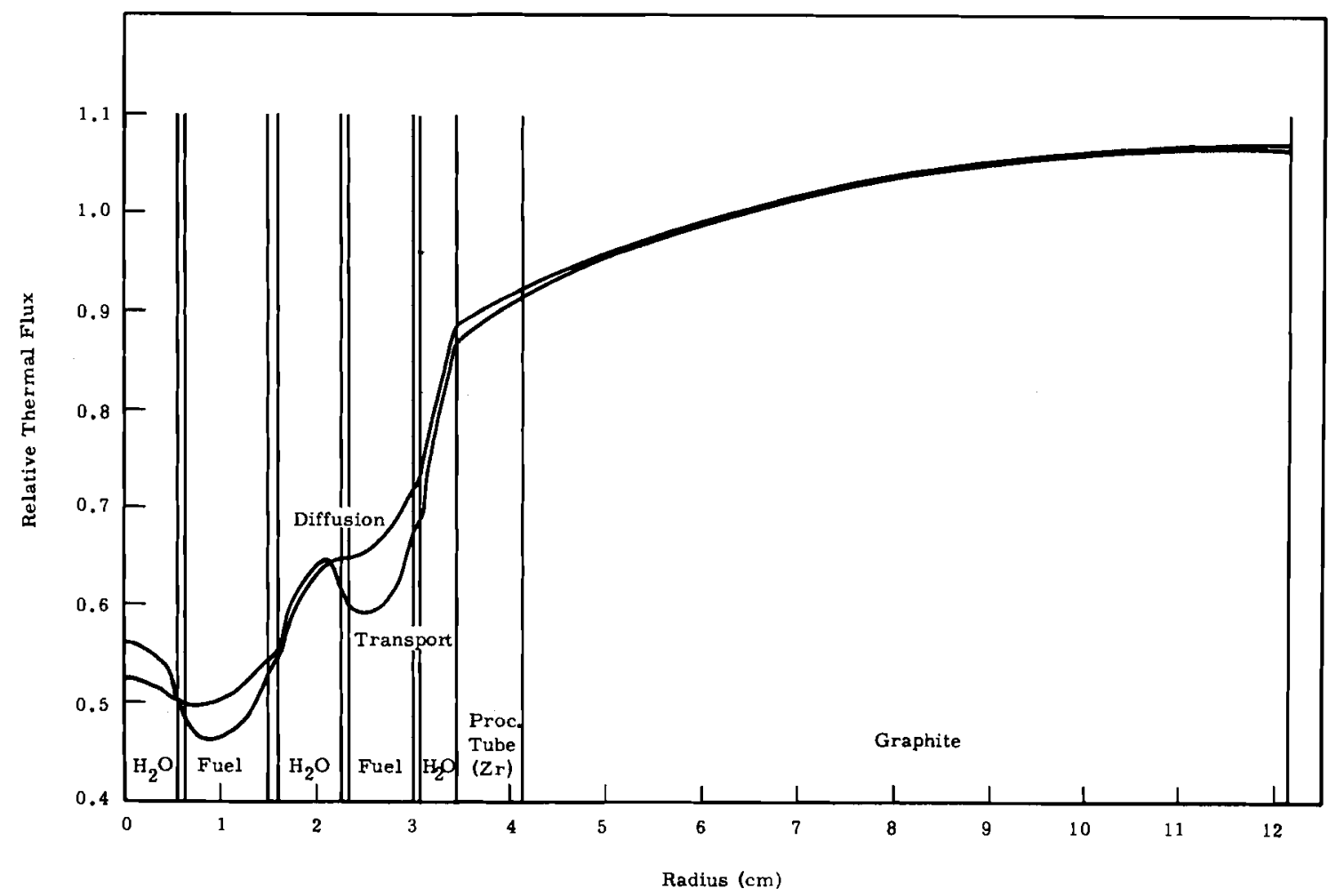

FIGURE 1

Comparison of Diffusion Theory and Transport

Theory Thermal Fluxes - "Cold" 


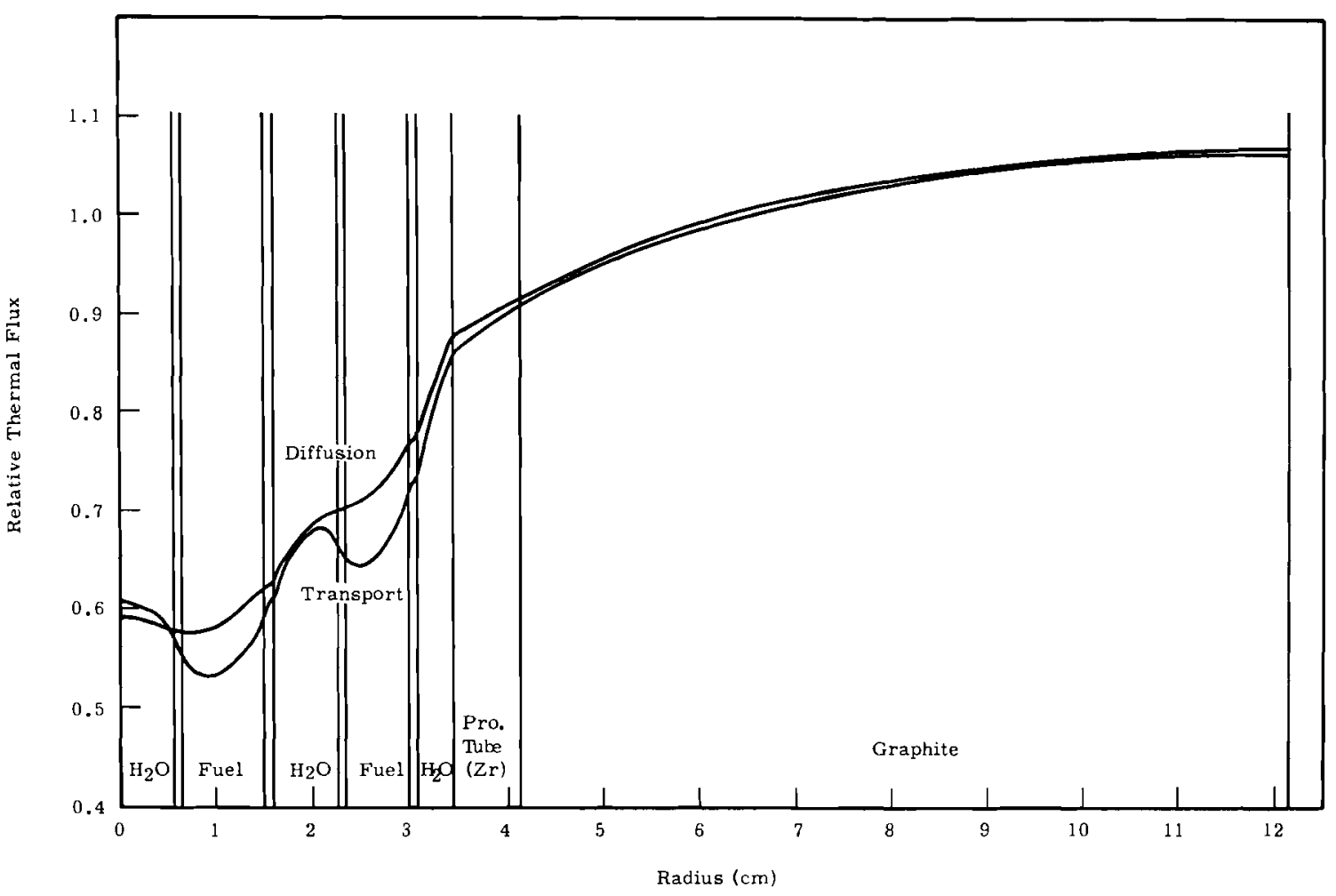

FIGURE 2

Comparison of Diffusion Theory and Transport

Theory Thermal Fluxes - "Hot"

TABILE II

REGION ABSORPTION RATES

Cold Case

\begin{tabular}{|c|c|c|c|c|c|}
\hline \multirow[b]{2}{*}{ Region } & \multirow[b]{2}{*}{ Material } & \multicolumn{2}{|c|}{ Thermal Absorption Rate } & \multicolumn{2}{|c|}{ Total Absorption Rate } \\
\hline & & Diffusion & Transport & Diffusion & Transport \\
\hline 1 & Water & 0.00217 & 0.00244 & 0.00171 & 0.00190 \\
\hline 2 & Zirconium & 0.00023 & 0.00024 & 0.00082 & 0.00083 \\
\hline 3 & Fuel & 0.23290 & 0.23677 & 0.24159 & 0.24506 \\
\hline 4 & Zirconium & 0.00094 & 0.00100 & 0.00322 & 0.00327 \\
\hline 5 & Water & 0.02184 & 0.02369 & 0.01669 & 0.01814 \\
\hline 6 & Zirconium & 0.00114 & 0.00115 & 0.00249 & 0.00324 \\
\hline 7 & Fuel & 0.65533 & 0.64339 & 0.62966 & 0.62033 \\
\hline 8 & Zirconium & 0.00158 & 0.00161 & 0.00425 & 0.00424 \\
\hline 9 & Water & 0.02897 & 0.03049 & 0.02210 & 0.02302 \\
\hline 10 & Zirconium & 0.02368 & 0.02532 & 0.05487 & 0.05564 \\
\hline 11 & Graphite & 0.03122 & 0.03389 & 0.02261 & 0.02434 \\
\hline
\end{tabular}

Hot Case

Thermal Absorption Rate Total Absorption Rate Diffusion Transport $\frac{\text { Total Absorption Rate }}{\text { Diffusion Transport }}$ $0.00182 \quad 0.00199$ 0.00138

0.00148

0. 00025

0.00026

0. 00092

0.00093

0. 25323

0. 25595

0. 25024

0. 00103

0.00109

0.00360

0. 25782

0. 01747

0.01873

0.01312

0.00363

0.00116

0.00119

0. 00279

0. 01383

0. 65816

0.65433

0. 62859

0,00352

0.00160

0.00165

0. 00460

0. 62281

0.02174

0.02300

0. 01611

0.00460

0.02225

0. 01854

0. 05776

0.01677

0.02128

0.02329

0.01488

0.05852

0.01607 
from the diffusion calculations are 6.4 and $10.2 \%$ less than those obtained from transport calculations for the inner and outer fuel regions, respectively. For the "hot" condition, they are 7.8 and $9.7 \%$ less (see Table III). If we examine the cell average broad group flux spectra (Table IV), it is noted that diffusion theory assigns a smaller relative importance to the thermal group by $5.4 \%$, in both bases, than that obtained using the transport approximation. This tends to cancel the effect on $\mathrm{k}_{\infty}$ of the difference in spatial thermal flux depression.

\section{TABLE III}

AVERAGE THERMAL FLUX

\begin{tabular}{|c|c|c|c|c|c|}
\hline \multirow[b]{2}{*}{ Region } & \multirow[b]{2}{*}{ Material } & \multicolumn{2}{|c|}{ "Cold" Case } & \multicolumn{2}{|c|}{ "Hot" Case } \\
\hline & & Diffusion & Transport & Diffusion & Transport \\
\hline 1 & Water & 0.5119 & 0.5334 & 0.5848 & 0.5870 \\
\hline 2 & Zirconium & 0.4983 & 0.4912 & 0.5779 & 0.5557 \\
\hline 3 & Fuel & 0.5122 & 0.4813 & 0.5927 & 0.5496 \\
\hline 4 & Zirconium & 0.5446 & 0.5381 & 0.6232 & 0.6044 \\
\hline 5 & Water & 0.6167 & 0.6181 & 0.6744 & 0.6631 \\
\hline 6 & Zirconium & 0.6482 & 0.6081 & 0.7014 & 0.6557 \\
\hline 7 & Fuel & 0.6738 & 0.6113 & 0.7279 & 0.6636 \\
\hline 8 & Zirconium & 0.7205 & 0.6793 & 0.7710 & 0.7283 \\
\hline 9 & Water & 0.8131 & 0.7909 & 0.8310 & 0.8060 \\
\hline 10 & Zirconium & 0.9043 & 0.8936 & 0.8970 & 0.8856 \\
\hline 11 & Graphite & 1.0350 & 1.0382 & 1.0305 & 1.0343 \\
\hline
\end{tabular}

TABLE IV

\section{CELL AVERAGED BROAD GROUP FLUX SPECTRA}

Energy Boundaries,

$\frac{\mathrm{eV}}{1.0 \times 10^{7}-1.17 \times 10^{4}}$

1. $17 \times 10^{4}-2.38$

2. $38-0.683$

$0.683-0$

\begin{tabular}{|c|c|c|}
\hline \multirow[b]{2}{*}{ Group } & \multicolumn{2}{|c|}{ "Cold" Case } \\
\hline & Diffusion & Transport \\
\hline 1 & 0.2918 & 0.2778 \\
\hline 2 & 0.2730 & 0.2652 \\
\hline 3 & 0.0369 & 0.0361 \\
\hline 4 & 0.3983 & 0.4209 \\
\hline
\end{tabular}

"Hot" Case Diffusion Transport

0. 2900

0.2756

0. 2741

0.2664

0.0368

0.0361

0.3991

0.4219

* Normalized to volume weighted cell average thermal flux. 
In fuel cycle studies the formulation of one group burnup cross sections is of importance. For a clean core the initial conversion ratio defined as, $\Sigma_{c}^{28} / \Sigma_{a}^{25}$, gives some indication of the expected isotopic transmutations. Initial conversion ratios were calculated, using both diffusion and transport results. The two methods agreed within about $1 \%$, which is judged to be quite good.

\section{CONCLUSIONS}

While it is recognized that transport calculations are in general preferable to diffusion calculations for discrete fuel geometries, it has been shown here that the errors introduced by using the diffusion approximation, although not negligible, are minor for the configurations considered. Care should be taken before extending these conclusions to other fuels or geometries. 


\section{REACTOR LATTICE PHYSICS}

\section{Determination of $\mathrm{k}_{\infty}$ for a $\mathrm{PuO}_{2}-\mathrm{UO}_{2}-$ Graphite Lattice}

T. B. Thornbury and N. A. Hill

The following summary has been prepared for presentation at the annual meeting of the American Nuclear Society in Gatlinburg, Tennessee.

A value for $\mathrm{k}_{\infty}$ was deduced from measurements of effective cross section ratios and from the mass of copper required to reduce the multiplication of a $\mathrm{PuO}_{2}-\mathrm{UO}_{2}$ fueled cell to one. The experiment was conducted in the Physical Constants Testing Reactor (PCTR) on a graphite-moderated air-cooled lattice fueled with 19 rod clusters of $0.5 \mathrm{in}$. diameter rods.

The composition and geometry of the cell whose multiplication is unity are given in Figure 1.

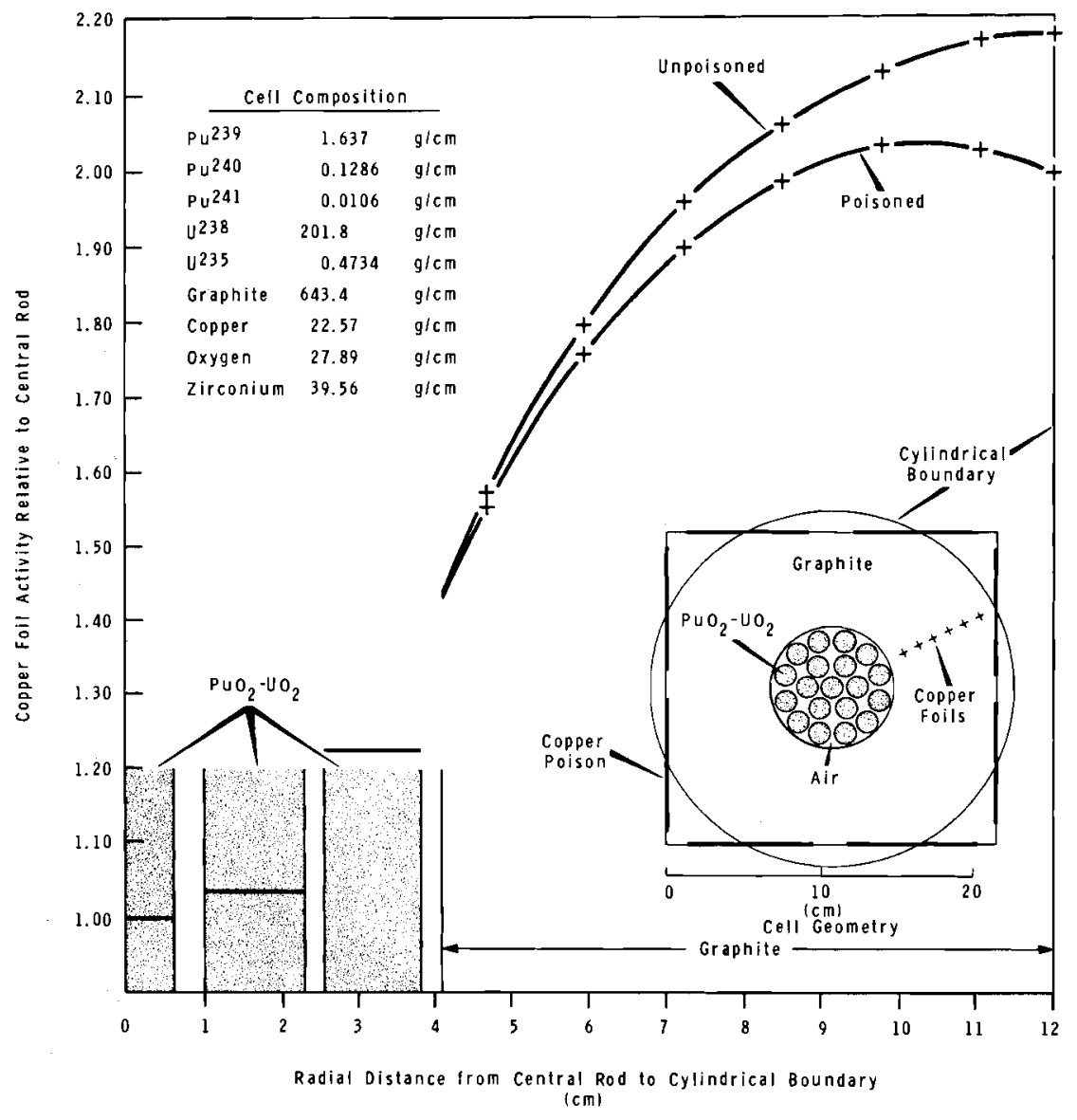

FIGURE 1 
The presence of plutonium in the system required a modification of the previously used method ${ }^{(1)}$ for determining $k_{\infty}$. Since $\eta$ of plutonium is notably dependent upon the neutron spectrum, changes in $\eta$ occur upon poisoning the cell.

The determination of $\mathrm{k}_{\infty}$ requires knowledge of lattice reaction rates. The plutonium and uranium fission rates in the $\mathrm{UO}_{2}-\mathrm{PuO}_{2}$ fuel were monitored using $\mathrm{U}^{235}-\mathrm{Al}$ and $\mathrm{Pu}-\mathrm{Al}$ foils placed in the fuel elements. The absorption rates in copper and the $1 / \mathrm{v}$ absorbers were monitored with copper foils placed in the fuel, graphite, and copper poison. The effective thermal absorption cross section of the $i^{\text {th }}$ cell component relative to the fission cross section of plutonium in the fuel

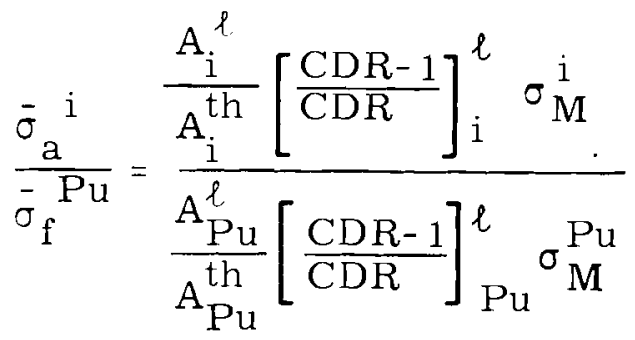

was determined from the fuel activities $A^{l}$ and $A_{\text {th }}$ obtained from foils simultaneously irradiated in the lattice and in the thermal column, respectively, the known cross section $\sigma_{M}$ in the thermal column, and the cadmium ratio (CDR) in the lattice. The thermal group extends to the cut-off for 0.040 in. cadmium $(0.64 \mathrm{eV})$; thus, the $0.3 \mathrm{eV}$ resonance of $\mathrm{Pu}^{239}$ is in the thermal group. The effective thermal fission cross section ratios for $\mathrm{Pu}^{239}$ relative to $\mathrm{U}^{235}$ were measured in the center, intermediate and outer fuel rings and at the cell edge to be 1.905, 1.944, 2.004, and 2.148, respectively, for the poisoned lattice. These ratios were normalized to the value 1.393 in the thermal column.

(1) R. E. Heineman. "Experience in the Use of the Physical Constants Testing Reactor, " Second United Nations International Conference on the Peaceful Uses of Atomic Energy, vol. 12, pp. 650-61. 1958. 
$\mathrm{k}_{\infty}=\frac{[\eta \mathrm{f}]^{\text {Thpoisoned }}}{[\eta \mathrm{f}]^{\text {poisoned }}}=\frac{\left[\frac{\mathrm{M}_{\mathrm{Pu}} \bar{\sigma}_{\mathrm{a}}^{\mathrm{Pu}}}{239 \bar{\sigma}_{\mathrm{fu}}^{\mathrm{Pu}}}+\sum_{i} \frac{\mathrm{M}_{\mathrm{i}} \bar{\sigma}_{\mathrm{a}}^{\mathrm{i}}}{\mathrm{N}_{\mathrm{i}} \overline{\bar{\sigma}}_{\mathrm{fu}}^{\mathrm{Pu}}}\right]^{\text {poisoned }}}{\left[\frac{\mathrm{M}_{\mathrm{Pu}} \bar{\sigma}_{\mathrm{Pu}}^{\mathrm{Pu}}}{239 \bar{\sigma}_{\mathrm{f}}^{\mathrm{Pu}}}+\sum_{\mathrm{i}} \frac{\mathrm{M}_{\mathrm{i}} \bar{\sigma}_{\mathrm{a}}^{\mathrm{i}}}{\mathrm{N}_{\mathrm{i}} \bar{\sigma}_{\mathrm{f}}^{\mathrm{P}}}\right]^{\text {unpoisoned }}}=1.21 \pm 0.01$

was calculated by combining the measured masses $\mathbf{M}_{i}$ and the atomic weights $\mathrm{N}_{i}$ with the effective cross sections ratios. The largest contribution to the error in the value of $\mathrm{k}_{\infty}$ is due to an estimated $\pm 1.6 \%$ uncertainty in the calculated value for $\left(\frac{\vec{\sigma}_{a}}{\vec{\sigma}_{f}}\right)^{P u}$. 


\section{CRITICAL MASS PHYSICS}

Critical Experiments with PuO 2 -Polystyrene Compacts

$$
\mathrm{Pu}^{240}=8.0 \%, \mathrm{H} / \mathrm{Pu}=15
$$

C. R. Richey and J. D. White

A series of critical experiments have been completed with homogeneous $\mathrm{PuO}_{2}$-polystyrene compacts (hydrogen-to-plutonium atomic ratio $=15$ ) having $8.0 \% \mathrm{Pu}^{240}$. These data are applicable to the intervening systems of wet powders, precipitates, slurries, polymers and oth 2 r highly concentrated plutonium mixtures encountered in chemical plants processing reactor fuels. Data from similar experiments with $2.2 \% \mathrm{Pu}^{240}$ compacts were previously reported. ${ }^{(1,2)}$ The $\mathrm{PuO}_{2}$-polystyrene compacts were fabricated by pressing 100-mesh polystyrene and $\mathrm{PuO}_{2}$ into a 2 in. cubic mold. Each compact was spray painted with about a 1 mil thick coat of aluminum paint and covered with rubberized plastic approximately 10 mils thick. The plutonium concentration in the compacts was $1.05 \mathrm{~g} / \mathrm{cm}^{3}$ and the density of the polystyrene was was $0.85 \mathrm{~g} / \mathrm{cm}^{3}$.

Critical arrays in the form of rectangular prisms ranging from near cubes, to long columns, to thin slabs were assembled using the Remote Split-Table Machine. (3) The arrays were enclosed on all surfaces by 6 in. of Plexiglas $\left(\rho=1.2 \mathrm{~g} / \mathrm{cm}^{3}\right)$. It was previously shown in the $2.2 \% \mathrm{Pu} 240$ experiments that the reflector savings from 6 in. of Plexiglas is equivalent

(1) C. R. Richey, J. D. White, E. D. Clayton, S. R. Bierman, K. L. Garlid, and D. R. Skeen. "Critical Experiments with $\mathrm{PuO}_{2}-$ Polystyrene Compacts, "Physics Research Quarterly Report, July, August, September, 1963, HW-79054, pp. 54-63 (General Electric Company, Richland, Washington). October 15, 1963.

(2) C. R. Richey, J. D. White, R. C. Lloyd, and E. D. Clayton. "Critical Experiments with $\mathrm{PuO}_{2}$-Polystyrene Compacts, " Physics Research Quarterly Report, October, November, December, 1963, HW-80020, pp. 31-37 (General Electric Company, Richland, Washington). January 15, 1964.

(3) C. R. Richey, E. D. Clayton, R. H. Odegaarden, J. D. White, W. A. Reardon. Hazard Summary Report for the Hanford Plutonium Critical Mass Laboratory, Supplement No. 1 - The Remote Split Table Machine, HW-66266 SUP 1 REV (General Electric Company, Richland Washington). October, 1963. 
to that of an infinitely thick layer. The safety and control rods utilized in these experiments were of the reflector displacement type, hence, the fuel cores were relatively free of extraneous materials.

Source-neutron multiplication measurements served as a guide for succeeding fuel addition during the assembly of the critical arrays. Spontaneous fission, primarily from $\mathrm{Pu}^{240}$, supplied the required neutron source. Three proportional neutron counters with scaling circuits provided the quantitative measurements of the source-neutron multiplication. Although each experimental array was made critical, criticality was usually achieved with a partial or incomplete layer of compacts and with the control rod partially inserted; therefore, the critical dimensions were obtained from a least squares analysis of the inverse neutron multiplication data. The data utilized in the analysis was obtained with greater than $80 \%$ of the critical mass assembled.

Except for partial reflection by Plexiglas control and safety rods, an otherwise bare-near cubic array of the $8.0 \% \mathrm{Pu}^{240}$ compacts was made critical with a 1 in. layer of $2.2 \% \mathrm{Pu}^{240}$ compacts on its top surface. The layer of $2.2 \% \mathrm{Pu}^{240}$ compacts was necessary because the number of $8.0 \%$ $\mathrm{Pu}^{240}$ compacts available was not sufficient for criticality. A least squares analysis of the source-neutron multiplication data with both reflecting rods withdrawn provided the critical size for the completely bare array. Approximately $98 \%$ of the bare critical mass was assembled when the rod reflecting array became critical. The perturbation due to the layer of $2.2 \% \mathrm{Pu}^{240}$ compacts was evaluated by an 18 group diffusion theory calculation; the correction increased the critical height by $1.3 \%$.

The critical dimensions for each array are recorded in Table I. Quoted errors are standard deviations from the least squares analysis of the inverse neutron-multiplication data and do not reflect any uncertainties in individual source-neutron multiplication measurement. Also given are data corrected to "clean arrays" free from extraneous materials. The basis for the corrections are as follows: 
The 1/16 in. thick aluminum plate and low density honeycomb base on which the bare array rested were evaluated by placing a duplicate arrangement on the top surface of the bare array. The corresponding correction increased the critical height by $0.16 \neq 0.03 \mathrm{~cm}$. To evaluate the effect of the plastic coating on each compact, its thickness was varied by inserting rubberized plastic shims between each compact. Measurements were made for both the bare and reflected near cubic arrays. Adding the shims increased the horizontal dimensions, and the critical height was observed to vary inversely as the plastic thickness. The critical volumes, however, behaved differently; as the shim thickness increased, the critical volume decreased for the bare array and increased for the reflected array. The correction for the plastic coating increased the critical volume of the bare array by $1.0 \%$ and decreased the critical volume of the reflected array by $0.5 \%$. Since the volume correction for the near-cubic array was small $(<1 \%)$, the critical dimensions for the reflected arrays were not altered on correcting to clean arrays. Corrections were applied, however, to the critical mass values for differences in the effective plutonium density.

\section{TABLE I}

CRITICALITY DATA FOR PUO 2 -POLYSTYRENE COMPACTS

$$
\mathrm{H} / \mathrm{Pu}=15, \mathrm{Pu}^{240}=8.0 \%
$$

\begin{tabular}{|c|c|c|c|c|c|}
\hline \multirow[b]{2}{*}{ Reflector } & \multicolumn{3}{|c|}{ Critical Dimensions, $\mathrm{cm}$} & \multicolumn{2}{|c|}{ Critical Mass, $\mathrm{Kg}$ of $\mathrm{Pu}$} \\
\hline & Length & Width & Height & Exp. Data & Corr. Data $(a)$ \\
\hline Plexiglas & 51.31 & 68.25 & $10.36 \pm 0.03$ & $37.19 \pm 0.11$ & $38.09 \pm 0.11$ \\
\hline Plexiglas & 35.92 & 35.92 & $15.42 \pm 0.03$ & $20.39 \pm 0.04$ & $20.89 \pm 0.04$ \\
\hline Plexiglas & 30.78 & 30.78 & $18.56 \pm 0.02$ & $18.07 \pm 0.02$ & $18.46 \pm 0.02$ \\
\hline Plexiglas & 25.65 & 25.65 & $25.03 \pm 0.05$ & $16.88 \pm 0.03$ & $17.29 \pm 0.03$ \\
\hline Plexiglas & 25.65 & 25.65 & $25.13 \pm 0.03$ & $16.95 \pm 0.02$ & 17. $36 \pm 0.02$ \\
\hline Plexiglas & 20.52 & 20.52 & $49.15 \pm 0.01$ & $21.22 \pm 0.01$ & $21.73 \pm 0.01$ \\
\hline Bare & 35.92 & 35.92 & $35.54 \pm 0.02$ & $46.93 \pm 0.03$ & $48.04 \pm 0.80$ \\
\hline Bare $e^{(b)}$ & 35.63 & 35.63 & $36.04 \pm 0.60$ & & \\
\hline
\end{tabular}

(a) Data corrected for plastic coating. An additional correction for the base material was applied to the bare arrays.

(b) Critical dimensions for bare arrays corrected for plastic coating and base material. 


\section{ANALYSIS OF EXPERIMENTS}

A constant buckling conversion scheme was used to obtain critical dimensions for the basic geometrical shapes (e.g., spheres, infinite slabs, and infinitely long cylinders). The critical buckling for the bare array was calculated by the usual one-group expression

$$
\mathrm{B}_{\mathrm{C}}^{2}=\frac{\pi^{2}}{(\mathrm{a}+2 \lambda)^{2}}+\frac{\pi^{2}}{(\mathrm{~b}+2 \lambda)^{2}}+\frac{\pi^{2}}{(\mathrm{c}+2 \lambda)^{2}}
$$

where a, b, and c are the critical dimensions of the arrays. The extrapolation length $\lambda$ is defined by

$$
\lambda=1 / 2\left(\mathrm{~T}_{\mathrm{e}}-\mathrm{T}_{\mathrm{c}}\right)
$$

where $\mathrm{T}_{\mathrm{e}}$ and $\mathrm{T}_{\mathrm{c}}$ are critical heights computed from an 18-group diffusion theory calculation using two different exterior boundary conditions. $T_{e}$ was computed with the group fluxes vanishing at the exterior boundary (albedo $=-1.0$ ) and $T_{c}$ computed using the usual boundary condition that the group fluxes vanish at the extrapolated boundary (albedo $=3.15 \times 10^{-2}$ ). The computed $\lambda$ for the near cubic bare array is $2.76 \mathrm{~cm}$ which corresponds to a critical buckling of $173.3 \pm 1.3 \mathrm{~m}^{-2}$.

Equating $\mathrm{B}_{\mathrm{C}}^{2}$ to the corresponding bare array value, extrapolation lengths for the reflected arrays are obtained upon substituting their respective critical dimensions into Equation (1); the resulting values of $\lambda$ are plotted in Figure 1 as a function of horizontal buckling, $\mathrm{B}_{\mathrm{H}}^{2}$. Corresponding values of $\lambda$ are also given for the $2.2 \% \mathrm{Pu}^{240}$ compacts. The errors indicated in Figure 1 are standard deviations reflecting the respective uncertainty in the measured critical height. A least squares analysis of the data gave extrapolation lengths of $7.53 \pm 0.03$ and $8.24 \pm 0.05 \mathrm{~cm}$, respectively, for the 2.2 and $8.0 \% \mathrm{Pu}^{240}$ reflected infinite slabs. Corresponding values calculated from Equation (2) were 7.51 and $8.22 \mathrm{~cm}$, respectively. The measured critical heights for reflected rectangular prisms of 2.2 and $8.0 \% \mathrm{Pu}^{240}$ arrays are given in Figure 2. 


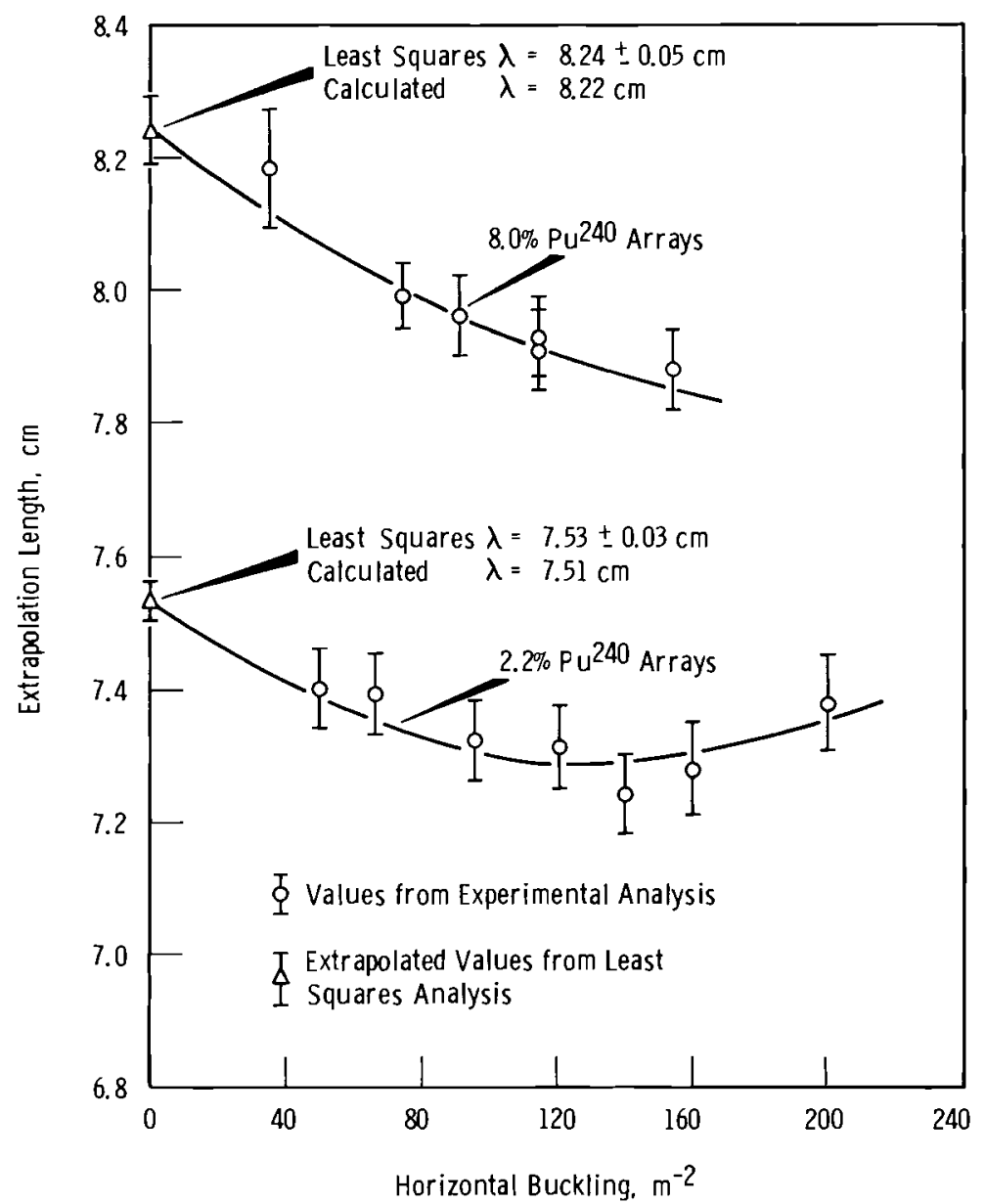

FIGURE 1

Extrapolation Length as a Function of Horizontal Buckling for $\mathrm{PuO}_{2}$-Polystyrene Compacts

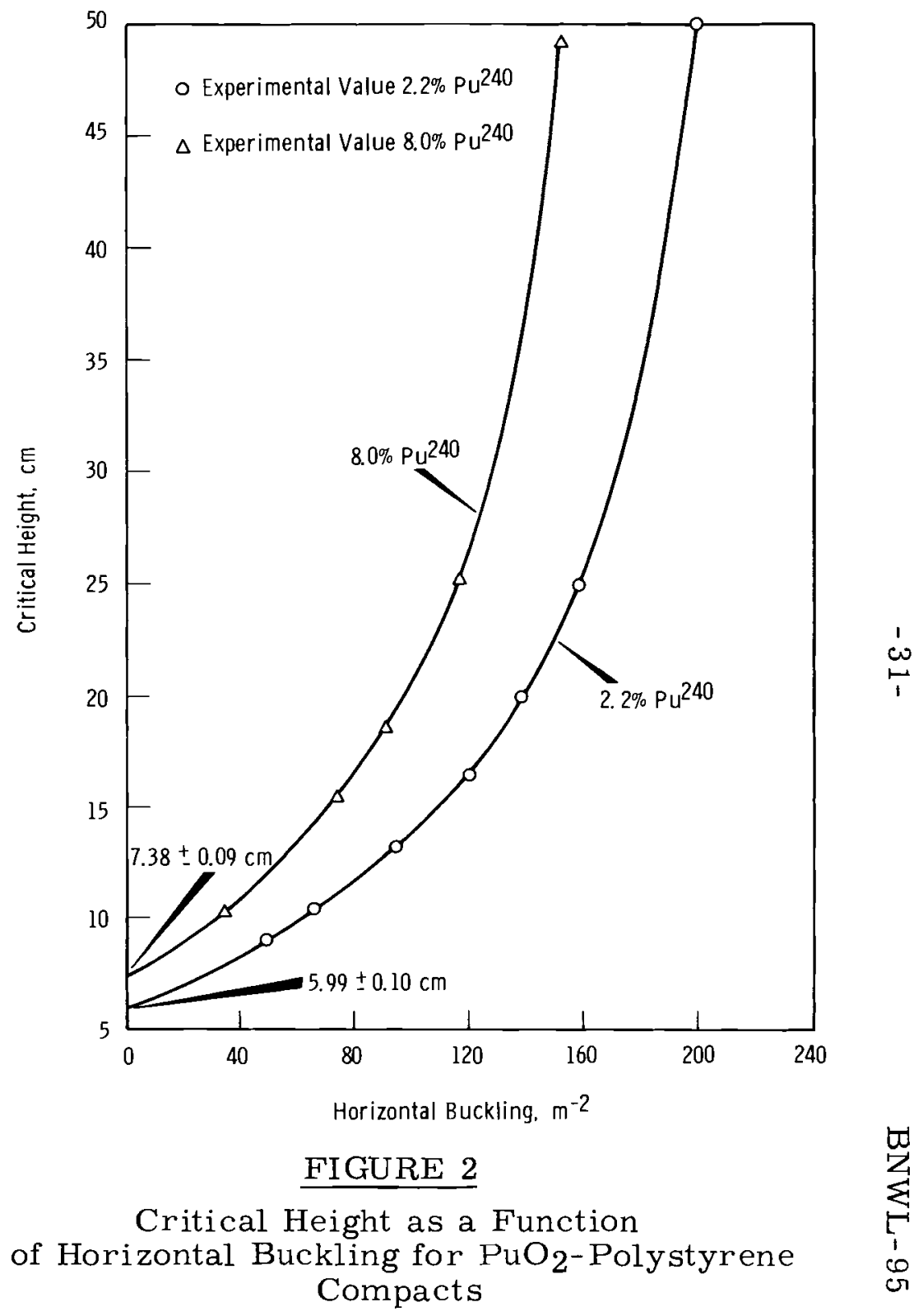


Critical dimensions for bare and Plexiglas-reflected spheres, cubes, infinite slabs, and infinitely long cylinders from constant buckling conversions are given in Table II. The values of $\lambda$ utilized in the buckling conversions were computed from Equation (2) except for the reflected cubes and slabs which were taken from Figure 1. Quoted errors in the critical dimensions are standard deviations reflecting the uncertainties in the measured critical heights and extrapolation lengths. The uncertainties in the calculated extrapolation lengths were estimated to be $\pm 0.2 \mathrm{~cm}$.

\section{TABLE II}

CRITICAL DIMENSIONS FOR PUO 2-POLYSTYRENE IN SPHERICAL, CYLINDRICAL, CUBIC, AND SLAB GEOMETRY: H/Pu $=15, \mathrm{Pu}^{240}=8.0 \%$

\begin{tabular}{|c|c|c|c|c|}
\hline \multirow[b]{2}{*}{ Geometry } & \multicolumn{2}{|c|}{ Bare Arrays } & \multicolumn{2}{|c|}{ Plexiglas Reflected Arrays } \\
\hline & $\lambda, \mathrm{cm}$ & $\underline{x}_{c} \stackrel{(a), c m}{c}$ & $\lambda, \mathrm{cm}$ & $\mathrm{x}_{\mathrm{c}}^{(\mathrm{a})}, \mathrm{cm}$ \\
\hline Infinite Slab & $2.69 \pm 0.20$ & $18.48 \pm 0.41$ & $8.24 \pm 0.05$ & $7.38 \pm 0.09$ \\
\hline Sphere & $2.69 \pm 0.20$ & $21.17 \pm 0.21$ & $8.22 \pm 0.20$ & $15.64 \pm 0.21$ \\
\hline $\begin{array}{l}\text { Infinite } \\
\text { Cylinder }\end{array}$ & $2.68 \pm 0.20$ & $15.59 \pm 0.21$ & $8.23 \pm 0.20$ & $10.04 \pm 0.21$ \\
\hline Cube & $2.76 \pm 0.20$ & $35.82 \pm 0.26$ & $7.82 \pm 0.06$ & $25.70 \pm 0.17$ \\
\hline
\end{tabular}

(a) $\mathrm{X}_{\mathrm{c}}$ denotes the initial dimensions; $\mathrm{i}$. e., thickness of slab, radii of sphere and cylinder.

\section{MULTIGROUP ANALYSIS}

The critical dimensions of $\mathrm{PuO}_{2}$-polystyrene in form of bare and Plexiglas reflected spheres, infinite slabs, and infinitely long cylinders were computed using multigroup diffusion and $\mathrm{S}_{4}$ approximations to the transport equation. $(1,2)$ Corresponding calculations were made for bare and water-reflected mixtures of $\mathrm{Pu}^{239}$-water ( $\rho=1.62 \mathrm{~g} \mathrm{Pu}{ }^{239} / \mathrm{cm}^{3}$ ) and $\mathrm{PuO}_{2}-$ water $\left(\rho=1.50 \mathrm{~g} \mathrm{Pu}^{239} / \mathrm{cm}^{3}\right)$ at a hydrogen-to-plutonium atomic ratio of 15. The results are summarized in Table III. The $\mathrm{S}_{4}$ calculations in general

(1) J. R. Lilley. Computer Code HFN-Multi-Group Multi-Region Neutron Diffusion Theory in One Space Dimension, HW-71545 (General Electric Company, Richland, Washington). November 17, 1961.

(2) B. G. Carlson, W. J. Worlton, G. Guber, and M. Shapiro. DTF Users Manual, UNC Phys/Math-3321, vol. I. 
TABLE III

CALCULATED CRITICALITY FOR PuO 2 -POLYSTYRENE, Pu 239 -WATER, AND $\underline{\mathrm{Pu}^{239} \mathrm{O}} 2$-WATER MIXTURES IN VARIOUS GEOMET RICAL SHAPES, H/Pu $=15$

\begin{tabular}{|c|c|c|c|c|c|c|c|c|c|}
\hline \multicolumn{3}{|c|}{$\begin{array}{c}\mathrm{PuO}_{2} \text {-Polystyrene, } \\
\mathrm{Pu}_{240}=2.2 \%\end{array}$} & \multicolumn{3}{|c|}{$\begin{array}{c}\mathrm{PuO}_{2} \text { - } \mathrm{Poly} \text { styrene, } \\
\mathrm{Pu} 240=8.0 \%\end{array}$} & \multicolumn{2}{|c|}{$\begin{array}{l}\mathrm{Pu}^{239}-\text { Water } \\
\mathrm{Pu}^{240}=0.0\end{array}$} & \multicolumn{2}{|c|}{$\begin{array}{c}\mathrm{Pu}^{239} \mathrm{O}_{2} \text {-Water } \\
\mathrm{Pu}^{240}=0.0\end{array}$} \\
\hline $\begin{array}{c}\operatorname{Exp},(a) \\
\mathrm{cm}\end{array}$ & $\begin{array}{l}\mathrm{P}_{1} \mathrm{Calc}, \\
\mathrm{cm}\end{array}$ & $\begin{array}{l}\mathrm{S}_{4} \mathrm{Calc}, \\
\mathrm{cm} \\
\end{array}$ & $\begin{array}{l}\text { Exp, } \\
\mathrm{cm}\end{array}$ & $\begin{array}{c}\mathrm{P}_{1} \mathrm{Calc}, \\
\mathrm{cm} \\
\end{array}$ & $\begin{array}{l}\mathrm{S}_{4} \mathrm{Calc} \\
\quad \mathrm{cm} \\
\end{array}$ & $\begin{array}{c}\mathrm{P}_{1} \text { Calc, } \\
\mathrm{cm} \\
\end{array}$ & $\begin{array}{l}\mathrm{S}_{4} \mathrm{Calc}, \\
\mathrm{cm}\end{array}$ & $\mathrm{P}_{1 \mathrm{~cm}} \mathrm{Calc}$ & $\begin{array}{c}\mathrm{S}_{4} \mathrm{Calc}, \\
\mathrm{cm}\end{array}$ \\
\hline
\end{tabular}

Inf. Slab Thickness $16,09 \pm 0,41$ Radius of Sphere $18.58 \pm 0.22$

16. 23

16.00
BARE ARRAYS

\section{Radius of Inf. Cyl.}

$13.64 \pm 0.21$

18. 71

18. 31

$18.48 \pm 0.41 \quad 18.98$

$21.17 \pm 0.21 \quad 21.69$

18.87

11. 90

11. 59

12. 42

12. 14

13. 75

13. 39

$15.59 \pm 0.21 \quad 15.97$

15.73

14. 19

13. 61

14. 70

14. 17

\section{REFLECTED ARRAYS ${ }^{(\mathrm{b})}$}

\begin{tabular}{|c|c|c|c|c|c|c|c|c|c|c|}
\hline Inf. Slab Thickness & $5.99 \pm 0.10$ & 6.17 & 6.21 & $7.38 \pm 0.09$ & 7. 98 & 8.02 & 4.54 & 4. 49 & 4.84 & 4.81 \\
\hline Radius of Sphere & $13.54 \pm 0.22$ & 13. 67 & 13.46 & $15.64 \pm 0.21$ & 15.97 & 15.90 & 10.82 & 10.34 & 11.23 & 10.78 \\
\hline Radius of Inf. Cyl. & $8.59 \pm 0.19$ & 8.70 & 8.53 & $10.04 \pm 0.21$ & 10.33 & 10.23 & 6.82 & 6.49 & 7. 12 & 6.81 \\
\hline
\end{tabular}

(a) Values derived from experimental data.

(b) $\mathrm{Pu} 239$-water and $\mathrm{Pu}^{239} \mathrm{O}_{2}$-water mixtures reflected by water; $\mathrm{PuO}_{2}$-polystyrene compacts reflected by $\mathrm{Plexiglas}$. 
agree better with experiment than do the diffusion theory results. Some difficulty in treating the $\mathrm{Pu}^{240}$ capture is evident from the difference in computed and experimental values for the $8.0 \% \mathrm{Pu}^{240}$ arrays.

The multigroup constant; for both the $\mathrm{S}_{4}$ and diffusion theory calculations were obtained from the GAMTEC-2 computer code. (1) The seventeen fast group constants ( $\mathrm{E}>0.683 \mathrm{eV}$ ) were averaged over a 64 -group slowing down spectrum from a $B_{1}$ approximation of the Boltzmann equation using a $\mathrm{Pu}^{239}$ fission spectrum weighted source term. The one thermal group constants were averaged over a Wigner-Wilkins spectrum using Sher normalized $\mathrm{Pu}^{239}$ cross sections. (2) Resonance absorption by $\mathrm{Pu}^{240}$ was treated by the Adler-Nordheim method. ${ }^{(3)}$ In the $\mathrm{S}_{4}$ calculations, the angular distribution of elastically scattered neutrons was defined through the $\mathrm{P}_{1}$ term in the Legendre expansion.

To convert the $\mathrm{PuO}_{2}$-polystyrene data to $\mathrm{Pu}^{239}$-water and $\mathrm{Pu}^{239} \mathrm{O}_{2}{ }^{-}$ water mixtures at an equivalent hydrogen-to-plutonium ratio requires more than a simple density correction. Polystyrene, $(\mathrm{CH})_{2}$, contains carbon in a one-to-one correspondence to hydrogen, whereas the hydrogen in water is in a two-to-one correspondence to oxygen. The presence of the additional carbon in polystyrene significantly affects the neutron leakage, and consequently, the critical mass. Since elastic scattering of neutrons by hydrogen is strongly forward in direction, displacement of hydrogen by the more symmetric scatterer, carbon, tends to reduce neutron leakage. This effect is particularly important at higher neutron energies $(E>0.01$ $\mathrm{MeV}$ ) where the cross sections for carbon are competitive to those for hydrogen.

(1) L. L. Carter, C. R. Richey, and C. E. Hughey. GAMTEC-2: A Code for Generating Consistent Multi-Group Constants Utilized in Diffusion and Transport Theory Calculations, BNWL-35. March, 1965.

(2) R. Sher and J. Felberbaum. 'Least Squares Analysis of $2200 \mathrm{~m} / \mathrm{sec}$ Parameters of $\mathrm{U}^{233}$, U235, and Pu239," Neutron Cross Section Evaluation Group, BNL-722 (Brookhaven National Laboratory). June, 1962.

(3) F. T. Adler, G. W. Hinman, and L. W. Nordheim. "The Quantitative Evaluation of Resonance Integral, "Proceedings of the Second International Conference on the Peaceful Uses of Atomic Energy, vol. 16, p. 1988. 1958. 
Making use of the previously reported 2. $2 \% \mathrm{Pu}^{240}$ data, the critical dimensions for bare and water-reflected spheres, infinite slabs, and infinitely long cylinders of $\mathrm{Pu}^{239}$-water $(\mathrm{H} / \mathrm{Pu}$ atomic ratio $=15)$ were obtain ed from

$$
\mathrm{X}\left(\mathrm{Pu}^{239}-\mathrm{H}_{2} \mathrm{O}\right)=\mathrm{X}_{\mathrm{exp}}\left(\mathrm{PuO}_{2}-\mathrm{CH}\right) \frac{\mathrm{X}_{\mathrm{calc}}\left(\mathrm{Pu}^{239}-\mathrm{H}_{2} \mathrm{O}\right)}{\mathrm{X}_{\mathrm{calc}}\left(\mathrm{PuO}_{2}-\mathrm{CH}\right)}
$$

where $\mathrm{X}_{\exp }\left(\mathrm{PuO}_{2}-\mathrm{CH}\right)$ is the experimentally derived critical dimension for the $2.2 \% \mathrm{Pu}^{240}$ compacts. $\mathrm{X}_{\text {calc }}\left(\mathrm{Pu}^{239}-\mathrm{H}_{2} \mathrm{O}\right)$ and $\mathrm{X}_{\text {calc }}\left(\mathrm{PuO}_{2}-\mathrm{CH}\right)$ are corresponding values from multigroup $\mathrm{S}_{4}$ calculations given in Table III. The resulting infinite slab thicknesses are $11.66 \pm 0.30$ and $4.36 \pm 0.12 \mathrm{~cm}$ for the bare and water-reflected slabs, respectively. Corresponding radii for infinitely long cylinders are $10.52 \pm 0.16$ and $6.54 \pm 0.16 \mathrm{~cm}$; radii for critical spheres are $13.81 \pm 0.16$ and $10.40 \pm 0.17 \mathrm{~cm}$. 
Prompt Neutron Decay Using Monte Carlo Methods of Analysis

L. L. Carter

Only under ideal situations is it possible to separate the space dependence from the time dependence in the equations describing the kinetic behavior of reactors. Monte Carlo techniques provide on ot the few methods for investigating systems where the space, time dependence may not be separated. The Monte Carlo calculation generally involves tracing a large number of neutrons and their progeny for a certain length of time. The position of each neutron at specified time intervals is recorded so that the neutron density as a function of time and position may be obtained. Since the length of the time trace required is generally a number of neutron generations, the calculation becomes quite time consuming. Therefore, it is desirable to investigate methods of obtaining the desired information with less computation. One such method would be to do a thorough analysis of only one neutron generation and try to extract the desired information from this data.

The total neutron density as a function of time integrated over the entire reactor may be obtained from an analysis of one neutron generation, providing the composition or geometry of the reactor is not changing with time. If $\mathrm{n}_{\mathrm{o}}$ fission neutrons are injected into a reactor, the total prompt neutron concentration after small time intervals $\Delta \mathrm{t}$ is given by:

$$
\begin{aligned}
n_{\Delta t}= & n_{o} f_{s l}+n_{o} \nu f_{f l}(1-\beta) \\
n_{2 \Delta t}= & n_{o} f_{s 2}+n_{o} \nu f_{f 2}(1-\beta)+n_{o}\left\{\nu f_{f l}(1-\beta)\right\}^{2}+n_{o} \nu f_{f l}(1-\beta) f_{s l} \\
n_{3 \Delta t}= & n_{o} f_{s 3}+n_{o} \nu f_{f 3}(1-\beta)+2 n_{o} \nu f_{f 2}(1-\beta)^{2} f_{f l}+n_{o} \nu f_{f 2}(1-\beta) f_{s 1} \\
& +n_{o}\left\{\nu f_{f l}(1-\beta)\right\}^{3}+n_{o}\left\{\nu f_{f l}(1-\beta)\right\}^{2} f_{s l}+n_{o} \nu f_{f l}(1-\beta) f_{s 2}
\end{aligned}
$$


where:

$f_{\text {si }}=$ fraction of original fission neutrons that do not suffer leakage or absorption in a time i $\Delta t$.

$f_{f i}=$ fraction of original fission neutrons that are absorbed and cause fission between times i $\Delta t$ and $(i-1) \Delta t$.

$\beta=$ total delayed neutron fraction.

Equation (1) may be expressed quite simply as a double summation:

$$
\begin{aligned}
& m_{p \Delta t}=\sum_{j=0}^{p-1} m_{j \Delta t} \nu f_{f, p-j}(1-\beta) \\
& n_{p \Delta t}=\sum_{j=0}^{p} m_{j \Delta t} f_{s, p-j}
\end{aligned}
$$

where initially $m_{0}$ is set equal to $n_{0}$.

Equations (2) and (3) may be used to compute the neutron density after a time $\ell \Delta t$ by allowing $p$ to assume the values $1,2,3, \ldots, l$ and solving first Equation (2) and then Equation (3) for each p value. Equation (2) is the fission source density. These equations are exact only as the time interval $\Delta$ approaches zero, but the solutions are normally acceptable for time intervals of about $5 \%$ of the average prompt neutron lifetime.

The $f_{s i}$ and $\nu f_{f i}$ values may be obtained by a Monte Carlo analysis of one generation of neutrons. The neutron lifetime at each absorption or leakage is tabulated and the following quantities are obtained after $\mathrm{n}$ neutron histories have been traced.

$$
\begin{aligned}
& v_{f i}=\sum_{j=1}^{n}\left(\frac{v \Sigma_{f}}{\Sigma_{a}}\right)_{i j} \delta_{i j} / n \\
& f_{R i}=\sum_{j=1}^{n} \delta_{i j} / n
\end{aligned}
$$




$$
f_{s i}=1-\sum_{j=1}^{i} f_{R j}
$$

where:

$$
\begin{aligned}
\delta_{i j}= & \text { unity if the neutron is absorbed ore removed from the } \\
& \text { system in time interval } i \text { and zero otherwise. } \\
\left(\nu \Sigma_{f} / \Sigma_{a}\right)_{i j}= & \text { the ratio of the macroscopic fission to absorption cross } \\
& \text { section times } \nu \text { at the absorption energy. }
\end{aligned}
$$

A sample calculation was made to demonstrate the feasibility of using this method to determine the prompt neutron decay. The SMC (Spherical Monte Carlo) computer code was used to trace one generation of neutrons. This is a three region Monte Carlo code for concentric spherical geometry. The energy loss of the neutron due to inelastic scattering events was determined from the evaporation model. The scattering distribution was assumed to be isotropic in the center of mass system for inelastic scattering. Elastic scattering events below $0.02 \mathrm{MeV}$ were assumed to be isotropic in the center of mass system. Above $0.02 \mathrm{MeV}$, the elastic scattering cross section as a function of angle was defined by the first six terms of a Legendre series.

$$
\sigma_{S}(E, \mu)=\frac{\sigma_{S}(E)}{2} \sum_{l=0}^{6} \alpha_{l} P_{l}(\mu)
$$

Average energy group cross sections were computed for 1440 energy groups. These cross sections were obtained from the RBU basic library. (1) The values of $\nu \mathrm{f}_{\mathrm{fi}}$ and $\mathrm{f}_{\mathrm{si}}$ were obtained from the Monte Carlo calculation by using Equations (4) and (6). A computer code was written to solve Equations (2) and (3) for the prompt neutron decay.

The sample problem was a relatively thermal reactor of plutonium nitrate solution. The $\mathrm{H} / \mathrm{Pu}$ atomic ratio was 124.8 and the $\mathrm{Pu}^{240}$ content in the plutonium was $4.6 \%$. S. R. Bierman measured the delayed critical

(1) R. C. Liikala. Data and Methods Employed in Updating the R. B. U. Basic Library, HW-75715 (General Electric Company, Richland, Washington). 1963. 
prompt neutron decay constant by a pulsed neutron method to be $385 \pm 26$ $\sec ^{-1}$. The corresponding Monte Carlo calculated decay constant was 392 $\sec ^{-1}$.

This analysis has not included the spacial dependence of the neutron density. This may also be included for a stable reactor (the geometry or fuel composition is not changing with time) by redefining Equations (2) and (3) as:

$$
\begin{aligned}
& \left(m_{p \Delta t}\right)_{r}=\sum_{l} \sum_{j=0}^{p-1}\left(m_{j \Delta t}\right)_{\ell}\left(\nu f_{f, p-j}\right) r, r(1-\beta) \\
& \left(n_{p \Delta t}\right)_{r} \sum_{l} \sum_{j=0}^{p}\left(m_{j \Delta t}\right)_{l}\left(f_{s, p-j}\right), r
\end{aligned}
$$

where:

$$
\begin{aligned}
\left(\mathrm{n}_{\mathrm{p} \Delta \mathrm{t}}\right)_{\mathrm{r}}= & \text { neutron density in volume } \mathrm{r} \text { after a time } \mathrm{p} \Delta \mathrm{t.} \\
\left(\mathrm{f}_{\mathrm{fp}}\right)_{\ell, r}= & \text { fraction of the fission neutrons born in volume } \ell \\
& \text { which cause fission in volume } \mathrm{r} \text { during the time interval } \\
& (\mathrm{p}-1) \Delta \mathrm{t} \text { to } \mathrm{p} \Delta \mathrm{t} . \\
\left(\mathrm{f}_{\mathrm{sp}}\right) \mathrm{l}, \mathrm{r}= & \text { fraction of the fission neutrons born in volume } \ell \text { which } \\
& \text { exist in volume } r \text { after a time interval } \mathrm{p} \Delta \mathrm{t} .
\end{aligned}
$$

The quantities ( $\mathrm{f}_{\mathrm{fp}}$ ) $\ell, \mathrm{r}$ and ( $\mathrm{fp}_{\mathrm{sp} \ell, \mathrm{r}}$ may be determined as before by an analysis of one generation of neutrons. However, the reactor must be divided into a large number of volume for Equations (8) and (9) to be valid. This would probably dictate the use of a computer with double precision arithmetic to solve the large summations involved in these equations.

In summary, the equations have been developed for determining the prompt neutron decay as a function of time and position from Monte Carlo techniques by analyzing one generation of neutrons. The assumption was made that the reactor geometry or fuel composition does not change with time. A sample calculation was successfully made to determine the integrated prompt neutron decay over the whole reactor using this method of analysis. 
Interpretation of Pulsed Neutron and Reactor Noise

Experiments in Reflected Reactors

R. W. Albrecht*

\section{INTRODUCTION}

It has become necessary to study the dynamic behavior of reflected critical assemblies in some detail in order to properly interpret experimental data arising from pulsed neutron and reactor noise measurements. This study is motivated by two considerations. First, the possibility that certain useful information can be gained from measurements in reflected systems concerning the separate dynamic parameters of the core and reflector as well as the coupling parameters of the core and reflector as well as the coupling paraters between the two. Second, to give a quantitative picture of the effects of a reflector in perturbing results which one would like to interpret based on bare, homogeneous reactor theory.

The material presented herein represents a preliminary, theoretical investigation of reflected reactor kinetics. It should be mentioned that the work is exploratory in nature and must be expanded further in order to adequately describe the systems in question. However, it is quite possible that the results of this study may help to improve the understanding of basic theory as well as remove some doubt from the interpretation of experimental data. Unfortunately, a detailed description of space-time effects will necessitate numerical solutions to the governing equations using a digital computer. However, it will be one object of this work to investigate the applicability of the simplest possible models -- those which may be open to relatively simple interpretation and solution.

\section{METHODS OF SOLUTION}

Point Reactor Kinetics

Three possible methods of solution to the basic kinetics equations present themselves. One of these is a method which utilizes the point kinetics formulation and expresses the neutron density, $N(\underline{r}, t)$ as an

*Dr. R. W. Albrecht, Dèpartment of Nuclear Engineering, University of Washington, Consultant to Battelle-Northwest Plutonium Critical Mass Laboratory. 
amplitude, $T(t)$ times a shape function $\eta(r, t)$. The basic shape function, $\eta(r, t)$, is time dependent, ${ }^{(1)}$ but in some cases a reasonable approximation may be found by considering a time-independent shape function. This may be reasonable for small reactors, even with a reflector, but the theory does not provide a measure of the possible error.

\section{Nodal Analysis}

A second method of attacking the problem is the method of nodal analysis. In this case, the reactor is broken up into regions or "nodes" and a set of time-dependent equations involving the average fluxes at each node is written. The difficult problem is the determination of parameters governing neutron leakage between nodes or, alternatively, an equivalent reactivity for each node.

One advantage of the nodal method is that this method is readily adaptable to the digital computer when the nodes are closely spaced. Unfortunately, if a large number of time steps are required, the solution of such a problem may require an inordinate amount of computer time. Although solutions may be found from a "fine mesh" nodal problem, this method is not very attractive for making general statements concerning reflected kinetic behavior.

If only a few nodes are used such that each node represents a large region of the reactor (such as the core and reflector in a "two-node" problem) then one has considerable difficulty in specifying uniquely the lumped parameters of each region as well as the coupling relations between regions. However, such a two-node analysis may be very illuminating because of the relatively simple mathematics involved and it is worthwhile to try to push this type of analysis as far as possible.

\section{Modal Analysis}

In the modal analysis method of space-time problems one expands the neutron flux in a series of space-functions and endeavors to find the time dependence of these functions. Commonly, one chooses a series of orthogonal functions such as the solutions of the Helmholtz equation. However, it

(I) M. Ash. Nuclear Reactor Kinetics, McGraw-Hill, Inc. 1965. 
is possible to expand in other functions such as certain Green's functions or other space functions which may be synthesized from static solutions. One problem which arises in using other than orthogonal functions in an expansion is the difficulty in finding suitable expansion coefficients. Although techniques are available to accomplish this, they are not as straightforward as the use of the usual orthogonality properties.

It would seem to be especially profitable to use modal expansions in the analysis of reflected reactor dynamics since many of the results which one is seeking are related to the behavior of the "fundamental mode. " In fact, in applying the pulse neutron technique or the reactor noise technique to such assemblies one usually puts considerable effort into making sure that he is measuring the prompt decay constant of the fundamental mode and that the interference from other, faster decaying, modes is negligibly small.

However, as was mentioned earlier, it may be advisable to study higher mode behavior to isolate core and reflector parameters. It also seems quite possible that considerable insight into the relationships between modal and nodal analysis could be gained by comparative study.

When a reflected reactor is large and/or subcritical it becomes less possible to insure that only the fundamental mode is contributing to the measurement. Again, a space dependent analysis may be called for. 
TWO-NODE KINETICS EQUATIONS FOR REFLECTED REACTORS

\section{Nomenclature}

$\mathrm{n}_{\mathrm{c}}=$ total number of neutrons in the core (thermal)

$\mathrm{n}_{\mathrm{r}}=$ total number of neutrons in the reflector

$\ell_{\mathrm{c}}=$ prompt neutron lifetime in the core (thermal)

$\ell_{\mathrm{r}}=$ neutron lifetime in the reflector

$\mathrm{P}_{\mathrm{C}}=$ probability that a thermal neutron does not leak from core

$\mathrm{P}_{\mathrm{r}}=$ probability that a neutron which disappears in the reflector reappears in the core

$\mathrm{P}=$ resonance escape probability in the core

$C_{i}=$ total number of delayed neutron precursors of the $i^{\text {th }}$ kind in the core

$\beta_{i}=$ fraction of fission neutrons which are delayed neutrons of the $i^{\text {th }}$ type

$\lambda_{i}=$ decay constant of the $i^{\text {th }}$ type precursor

$\mathrm{k}_{\mathrm{th}}=$ infinite core reproduction factor from thermal neutrons

$\mathrm{k}_{\infty}=$ infinite core multiplication constant

$\mathrm{k}_{\mathrm{eff}}^{(\mathrm{c})}=$ the effective multiplication constant of the reflected core

$\Sigma_{\mathrm{f}}=$ macroscopic fission cross-section in the core

$\Sigma_{\mathrm{a}}=$ macroscopic absorption cross-section in the core

$\mathrm{g}_{\mathrm{c}}=$ probability that a fast neutron does not leak from the core

$\mathrm{P}_{\text {eff }}=$ an equivalent resonance escape probability for the reflected core

$\mathrm{K}_{\mathrm{eff}}^{(\mathrm{b})}=$ the effective multiplication constant of the bare core

$\ell^{* *}=$ the reflected reactor prompt neutron lifetime corresponding to the $1 / \mathrm{v}$ uniform poisoning experiment

$c=$ probability per unit time for small times that a neutron will be captured by an absorber

$\Delta=$ a change in multiplication constant

$\mathrm{k}_{\text {eff }}=$ overall multiplication constant for reflected reactor 
In this representation of reflected reactor kinetics equations we will write down a set of equations which consist of conservation relations for the core neutron population, reflector neutron population, and precursor population. The appropriate equations are found by carefully considering the mechanisms for neutron loss and gain. Thus, we have, both in equation form and in descriptive form:

$\frac{\mathrm{dn} \mathrm{c}_{\mathrm{c}}}{\mathrm{dt}}=-\frac{\mathrm{n}_{\mathrm{c}}}{\ell_{\mathrm{c}}}+\mathrm{Pg}_{\mathrm{c}} \sum_{i=1}^{\mathrm{N}} \lambda_{i} \mathrm{C}_{\mathrm{i}}+\mathrm{Pg}_{\mathrm{c}} \nu \Sigma_{\mathrm{f}}(1-\beta) \mathrm{v}_{\mathrm{c}} \mathrm{n}_{\mathrm{c}}+\mathrm{P}_{\mathrm{r}} \frac{\mathrm{n}_{\mathrm{r}}}{\ell_{\mathrm{r}}}+\mathrm{S}_{\mathrm{c}}$

$\left[\begin{array}{l}\text { rate of } \\ \text { change } \\ \text { of neu- } \\ \text { tron } \\ \text { popula- } \\ \text { tion in } \\ \text { core }\end{array}\right]=\left[\begin{array}{l}\text { total } \\ \text { disap- } \\ \text { pearance } \\ \text { rate of } \\ \text { neutrons } \\ \text { from the } \\ \text { core }\end{array}\right]+\left[\begin{array}{l}\text { rate of in- } \\ \text { crease of } \\ \text { core neu- } \\ \text { tron popu- } \\ \text { lation from } \\ \text { the decay of } \\ \text { delayed neu } \\ \text { tron precur } \\ \text { sors which } \\ \text { do not leak } \\ \text { while fast } \\ \text { and escape } \\ \text { resonance } \\ \text { while slow }- \\ \text { ing down }\end{array}\right]+\left[\begin{array}{l}\text { rate of in- } \\ \text { crease of } \\ \text { core neu- } \\ \text { tron popu- } \\ \text { lation from } \\ \text { prompt fis- } \\ \text { sion neutrons } \\ \text { which do not } \\ \text { leak while } \\ \text { fast and } \\ \text { escape reson- } \\ \text { ance capture }\end{array}\right]+\left[\begin{array}{l}\text { rate of } \\ \text { increase } \\ \text { of core } \\ \text { neutron } \\ \text { popula- } \\ \text { tion due } \\ \text { to reflec- } \\ \text { tor neu- } \\ \text { trons } \\ \text { being } \\ \text { returned } \\ \text { to core }\end{array}\right]+\left[\begin{array}{l}\text { total } \\ \text { extra- } \\ \text { neous } \\ \text { source } \\ \text { rate of } \\ \text { core } \\ \text { neutrons }\end{array}\right]$

$\frac{d n_{r}}{d t}=-\frac{n_{r}}{l_{r}}+\left(1-P_{c}\right) \frac{n_{c}}{l_{c}}+\left(1-g_{c}\right) \sum_{i=1}^{N} \lambda_{i} C_{i}+\left(1-g_{c}\right) v \Sigma_{f}(1-\beta) v_{c} n_{c}+S_{r}$

$\left[\begin{array}{l}\text { rate of } \\ \text { change } \\ \text { of neu- } \\ \text { tron pop- } \\ \text { ulation } \\ \text { in reflec }- \\ \text { tor }\end{array}\right]=\left[\begin{array}{l}\text { total } \\ \text { disap- } \\ \text { pearance } \\ \text { rate of } \\ \text { neutrons } \\ \text { from the } \\ \text { reflector }\end{array}\right]+\left[\begin{array}{l}\text { thermal neu- } \\ \text { tron leakage } \\ \text { rate into } \\ \text { reflector } \\ \text { from core }\end{array}\right]+\left[\begin{array}{l}\text { leakage rate } \\ \text { of fast, } \\ \text { delayed neu- } \\ \text { trons from } \\ \text { core into the } \\ \text { reflector }\end{array}\right]+$

$\left[\begin{array}{l}\text { leakage rate } \\ \text { of fast, } \\ \text { prompt neu- } \\ \text { trons into } \\ \text { reflector } \\ \text { from the } \\ \text { core assum- } \\ \text { ing these } \\ \text { neutrons } \\ \text { get distrib- } \\ \text { uted in } \\ \text { reflector } \\ \text { same as } \\ \text { thermal neu- } \\ \text { trons }\end{array}\right]+\left[\begin{array}{l}\text { neous } \\ \text { source } \\ \text { rate of } \\ \text { reflector } \\ \text { neutrons }\end{array}\right]$




$$
\begin{aligned}
& \frac{\mathrm{d} C_{i}}{\mathrm{dt}}=-\lambda_{i} \mathrm{C}_{i}+\beta_{i} \nu \Sigma_{f_{\mathrm{c}} \mathrm{n}_{\mathrm{c}} \mathrm{v}} \\
& {\left[\begin{array}{l}
\text { rate of } \\
\text { change of } \\
\text { precursors } \\
\text { of ith kind }
\end{array}\right]=\left[\begin{array}{l}
\text { decay rate } \\
\text { of pre- } \\
\text { cursors } \\
\text { of ith kind }
\end{array}\right]+\left[\begin{array}{l}
\text { production } \\
\text { rate of } \\
\text { precursors } \\
\text { of ith kind }
\end{array}\right]}
\end{aligned}
$$

Equations (1), (2), and (3) may be cast in a somewhat more compact form by defining

$$
\left\{\begin{aligned}
\nu \Sigma_{\mathrm{f}} v & =\frac{\nu \Sigma_{\mathrm{f}}}{\Sigma_{\mathrm{a}}} \frac{\mathrm{P}_{\mathrm{c}}}{\ell_{\mathrm{c}}} \\
\mathrm{k}_{\mathrm{th}} & =\nu \frac{\Sigma_{\mathrm{f}}}{\Sigma_{\mathrm{a}}}
\end{aligned}\right.
$$

where the core lifetime has been assumed to be given by the thermal neutron lifetime.

We then have

$$
\begin{aligned}
& \frac{\mathrm{dn}_{\mathrm{c}}}{\mathrm{dt}}=\frac{\mathrm{n}_{\mathrm{c}}}{l_{\mathrm{c}}}\left[\mathrm{k}_{\mathrm{th}} \mathrm{P}_{\mathrm{c}} \mathrm{Pg}_{\mathrm{c}}(1-\beta)-1\right]+\mathrm{P}_{\mathrm{r}} \frac{\mathrm{n}_{\mathrm{r}}}{l_{\mathrm{r}}}+\mathrm{Pg}_{\mathrm{c}} \sum_{i=1}^{N} \lambda_{i} \mathrm{C}_{i}+\mathrm{S}_{\mathrm{c}} \\
& \frac{\mathrm{dn} \mathrm{r}}{\mathrm{dt}}=-\frac{\mathrm{n}_{\mathrm{r}}}{l_{\mathrm{r}}}+\left(1-\mathrm{P}_{\mathrm{c}}\right) \frac{\mathrm{n}_{\mathrm{c}}}{l_{\mathrm{c}}}+\left(1-\mathrm{g}_{\mathrm{c}}\right)\left[\sum_{i=1}^{N} \lambda_{i} \mathrm{C}_{i}+\frac{\mathrm{n}_{\mathrm{c}}}{l_{c}}(1-\beta) \mathrm{k}_{\mathrm{th}} \mathrm{P}_{\mathrm{c}}\right]+\mathrm{S}_{\mathrm{r}} \\
& \frac{\mathrm{dC}}{\mathrm{dt}}=-\lambda_{i} \mathrm{C}_{i}+\beta_{i} \mathrm{n}_{\mathrm{c}} \mathrm{P}_{\mathrm{c}} \frac{\mathrm{k}_{\mathrm{th}}}{l_{\mathrm{c}}} .
\end{aligned}
$$

The critical condition is obtained by setting the derivatives and external sources to zero to obtain

$$
k_{t h} P_{c}\left[P_{c}+P_{r}\left(1-g_{c}\right)\right]=1-P_{r}\left(1-P_{c}\right)
$$


Condition (8) reduces to the condition that

$$
\mathrm{k}_{\text {th }} \mathrm{Pg}_{\mathrm{C}} \mathrm{P}_{\mathrm{c}}=\mathrm{k}_{\infty} \mathrm{P}_{\mathrm{C}} \mathrm{g}_{\mathrm{C}}=1
$$

when $\mathrm{P}_{\mathrm{r}}=0$ (i. e., in the case of a bare reactor).

An equivalent resonance escape probability, $P_{\text {eff }}$, which includes both core and reflector effects can be found by defining

$$
\mathrm{g}_{\mathrm{C}} \mathrm{P}_{\mathrm{eff}}=\mathrm{Pg}_{\mathrm{C}}+\mathrm{P}_{\mathrm{r}}\left(1-\mathrm{g}_{\mathrm{C}}\right)
$$

Using (10), an effective multiplication factor for the core, $k_{e f f}^{(c)}$, may be defined. This is equal to the left hand side of Equation (8) so that we have, for the critical condition.

$$
k_{\text {eff }}^{(c)}=k_{t h} P_{c} g_{c} P_{\text {eff }}=1-P_{r}\left(1-P_{c}\right) \text {. }
$$

This critical condition is the same as the one given by Cohn ${ }^{(1)}$ with the exception that the equivalent quanticy to $\mathrm{k}_{\mathrm{eff}}^{(\mathrm{c})}$ defined by Cohn is "probability that a disappearing core neutron will give rise to a new fission neutron in the core. "In order for the reflected reactor kinetics equations to reduce to the bare reactor kinetics equations when $\mathrm{P}_{\mathrm{r}}=0$ it is necessary that $\mathrm{k}(\mathrm{c})$ or an equivalent quantity be allowed to be larger than one. Clearly this is not the case if it is defined as a probability. Thus, Cohn's reflected reactor kinetics equations do not reduce to the bare reactor kinetics equations when viewed in the context of his own definitions.

To define an overall prompt neutron lifetime it is useful to define an effective multiplication constant for the bare core by

$$
\mathrm{k}_{\mathrm{eff}}^{(\mathrm{b})}=\mathrm{k}_{\mathrm{th}} \mathrm{PP}_{\mathrm{c}} \mathrm{g}_{\mathrm{c}}
$$

Using the critical condition, (8), we see that with Definition (12) this critical condition may be written as

$$
1-\mathrm{k}_{\mathrm{eff}}^{(\mathrm{b})}=\mathrm{P}_{\mathrm{r}}\left[\left(1-\mathrm{P}_{\mathrm{c}}\right)+\left(1-\mathrm{g}_{\mathrm{c}}\right) \mathrm{k}_{\mathrm{th}} \mathrm{P}_{\mathrm{c}}\right] \text {. }
$$

Defining the overall prompt neutron lifetime as that which is a result of a $1 / \mathrm{v}$ uniform poisoning experiment, we assume an absorber with a macroscopic cross section, $\mathrm{c} / \mathrm{v}$, is added uniformly to the core and reflector. 
Simultaneously, a change in multiplication constant, $\Delta$, is inserted to keep the reactor critical. At the new critical condition we have:

$$
\begin{aligned}
& \mathrm{n}_{\mathrm{c}}\left[\frac{\mathrm{k}_{\mathrm{th}}(1+\Delta) \mathrm{P}_{\mathrm{c}} \mathrm{Pg}_{\mathrm{c}}-1}{\ell_{\mathrm{c}}}-\mathrm{v}_{\mathrm{c}}\left(\frac{\mathrm{c}}{\mathrm{v}_{\mathrm{c}}}\right)\right]+\mathrm{P}_{\mathrm{r}} \frac{\mathrm{n}_{\mathrm{r}}}{l_{\mathrm{r}}}=0 \\
& \frac{\mathrm{n}_{\mathrm{c}}}{l_{\mathrm{c}}}\left[1-\mathrm{P}_{\mathrm{c}}+\left(1-\mathrm{g}_{\mathrm{c}}\right) \mathrm{k}_{\mathrm{th}} \mathrm{P}_{\mathrm{c}}\right]-\mathrm{n}_{\mathrm{r}}\left[\frac{1}{l_{\mathrm{r}}}+\mathrm{v}_{\mathrm{r}}\left(\frac{\mathrm{c}}{\mathrm{v}_{\mathrm{r}}}\right)\right]=0 .
\end{aligned}
$$

Setting the determinant of the coefficients in (14) and (15) to zero and substituting (12) and (13) into the results we obtain

$$
l^{*}=\frac{\Delta}{\mathrm{C}}=\frac{\ell_{\mathrm{C}}+\ell_{\mathrm{r}}\left(1-\mathrm{k}_{\mathrm{eff}}^{(\mathrm{b})}\right)}{\mathrm{k}_{\mathrm{eff}}^{(\mathrm{b})}} .
$$

Again, this equation has the same form as that derived by Cohn ${ }^{(1)}$ with the exception that in this case he again has "probability that a disappearing core neutron will give rise to a new fission neutron in the core, " instead of (in this case) $\mathrm{k}_{\mathrm{eff}}^{(\mathrm{b})}$. Thus Cohn's work makes no distinction between the effective multiplication constant of the core when the resonance escape probability is improved by the reflector and when the core is bare. Note the self consistency which persists in this derivation since $l^{*}$ is equal to $\ell_{\mathrm{C}}$ only when the effective multiplication constant of the bare core is equal to unity.

Thus, our basic kinetic equations have been derived and are intuitively satisfying since, with consistency of definition, they reduce to the bare reactor result when $\mathrm{P}_{r}=0$, they given a consistent definition of the mean lifetime, and they reduce to realistic critical conditions. These equations differ slightly from those given by Cohn ${ }^{(1)}$ and are considered an improvement.

An estimate of the difference between the kinetic equations just derived and Cohn's can be made by considering the ratio of the effective multiplication

(1) C. E. Cohn. "Reflected Reactor Kinetics, "Nuclear Science and Engineering, vol. 21. pp. 12 - 17. 1962. 
constant of the core with reflector to the effective multiplication constant of the bare core.

$$
\frac{k_{\text {eff }}^{(c)}}{k_{\text {eff }}^{(b)}}=1+\frac{P_{r}}{p} \frac{\left(1-g_{c}\right)}{g_{c}}=\frac{P_{\text {eff }}}{p}
$$

If there is no fast neutron leakage from the core (the core is very thermal) then $\mathrm{g}_{\mathrm{c}}=1$ and the two multiplication constants are equal. Alternatively, if the core is bare, $\mathrm{P}_{\mathrm{r}}=0$, the multiplication constants are equal as expected.

On the other hand, if there is a considerable amount of fast leakage then the ratio given in Equation (17) is greater than unity. This reflects the augmentation of the equivalent multiplication constant of the core due to the improvement of resonance escape probability (or the new neutron spectrum caused by reflected neuts) caused by the presence of the reflector. Thus, in contradistinction to Cohn's statement about his equation that ".... this equation holds even if the neutron energies in core and reflector are different" we show that the energy does make a difference. As a matter of fact, Cohn's analysis becomes increasingly more in error for increasing difference between the mean neutron energy in the core and reflector.

The kinetic equations given here differ considerably from those given by Randall and Griffin (1) as abstracted from Keaten and Griffin. (2) It can easily be shown that these latter equations are incorrect by observing that the critical condition is not correct as well as merely by noting the neutron conservation laws. Although the equations of Reference (2) will not be used here, this matter is called to the reader's attention since some other aspects of the work in Reference (1) will be relevant to the general problem of reflected reactor kinetics.

(1) R. L. Randall and C. W. Griffin. "Application of Power Spectra to to Reactor-Systems Analysis, "Noise Analysis in Nuclear Systems, pp. 107 - 134, Proceedings of Symposium, University of Florida, November 4 - 6, 1963. USAEC Publication. June, 1964.

(2) R. W. Keaten and C. W. Griffin. Reflected Reactor Kinetics, Atomics International, USAEC Report NAA-SR-7263. March 1, 1963. 


\section{DERIVATION OF SOURCE TRANSFER FUNCTIONS}

In order to study reactor noise characteristics it is necessary to have available certain transfer functions. We are interested in both critical and subcritical operation, so we include in our derivation the possibility that the reactor is subcritical. However, most applications will involve only high frequencies so we will neglect the time dependence of precursors.

To derive these transfer functions relating fluctuations in the neutron density in the core and reflector to fluctuations in source strength in these two regions we start with the basic kinetics equations

$$
\begin{aligned}
& \frac{d n_{c}}{d t}=\frac{n_{c}}{l_{c}}\left[k_{e f f}^{(b)}(1-\beta)-1\right]+\frac{n_{r}}{l_{r}} P_{r}+P_{c} \sum_{i=1}^{N} \lambda_{i} C_{i}+S_{c} \\
& \frac{d n_{r}}{d t}=-\frac{n_{r}}{l_{r}}+\left(1-P_{c}\right) \frac{n_{c}}{l_{c}}+\left(1-g_{c}\right)\left[\sum_{i=1}^{N} \lambda_{i} C_{i}+\frac{n_{c}}{l_{c}}(1-\beta) k_{t h} P_{c}\right]+S_{r} \\
& \frac{d C_{i}}{d t}=-\lambda_{i} C_{i}+\lambda_{i} n_{c} P_{c} \frac{k_{t h}}{l_{c}}
\end{aligned}
$$

For the "infinite delay time model" we set $\lambda_{i} C_{i}=\lambda_{i}{ }_{c} P_{c} \frac{k_{t h}}{l_{c}}$, Laplace Transform Equations (5), (6), and (7), and solve for either $\mathrm{n}_{\mathrm{C}}(\mathrm{s})$ or $\mathrm{n}_{\mathrm{r}}(\mathrm{s})$ in terms of the source fluctuations. Then, letting $s \rightarrow j \omega$ we get for the source transfer functions

$$
\begin{aligned}
& n_{c}(j \omega)=\frac{S_{c}(j \omega)\left(1+j \omega \ell_{r}\right) \ell_{c}+S_{r}(j \omega) P_{r} \ell_{c}}{k_{e f f}^{(b)}\left[j \omega \ell^{*}+\left(\frac{k_{e f f}^{(c)}}{k_{\text {eff }}^{(b)}}+j \omega \ell_{r}\right) \beta\right]+1-k_{e f f}-\omega^{2} \ell_{r} \ell_{c}}
\end{aligned}
$$

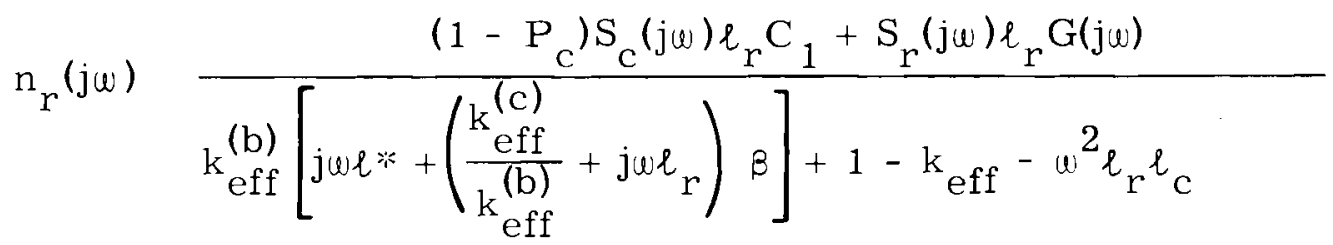


where

$$
C_{1}=1+\frac{k_{t h} P_{c}\left(1-g_{c}\right)}{1-P_{c}}-\frac{\beta k_{t h} P_{c}\left(1-g_{c}\right)}{1-P_{c}}
$$

and

$$
G(j \omega)=\frac{P_{r}\left(1-P_{c}\right) C+\text { denom }}{1+j \omega \ell_{r}}
$$

where "denom" means the denominator of the transfer function.

If $\mathrm{g}_{\mathrm{c}}=1, \mathrm{k}_{\text {eff }}^{(\mathrm{b})}=\mathrm{k}_{\text {eff }}^{(\mathrm{c})}$, and $\mathrm{k}_{\text {eff }}=1$, then Equations (18) and (19)

reduce to those of Cohn. (1)

We shall return to these transfer functions later when we derive the noise spectra for the reflected reactor.

The critical reactor transfer functions in the "infinite delay time" approximation are somewhat simpler than the subcritical transfer functions. For the core and reflector these are:

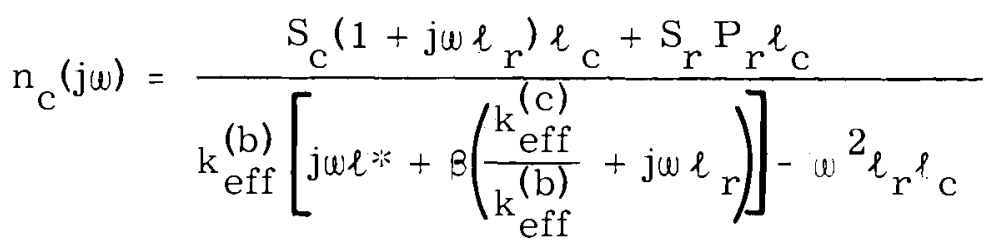

$$
\begin{aligned}
& n_{r}(j \omega)=\frac{S_{r}(j \omega) \ell_{r}\left[j \omega \ell_{c}-k_{\text {eff }}^{(c)}(1-\beta)+1+\text { other terms }\right]+S_{c}(j \omega) \ell_{r}\left(1-P_{c}\right)}{k_{\text {eff }}^{(b)}\left[j \omega \ell *+\beta\left(\frac{k_{\text {eff }}^{(c)}}{k_{\text {eff }}^{(b)}}+j \omega \ell_{r}\right)\right]-\omega^{2} \ell_{r^{\ell}}}
\end{aligned}
$$

DECAY CONSTANTS FOR CRITICAL, TWO REGION, REACTOR MODEL

Several computations were performed to study the relation between the various reactor parameters and the resulting decay constants or break frequencies in the two-node model. The purpose of this section is to derive a formula for these decay constants. In the next section the results of some of the computations will be discussed. 
The starting kinetics equations are again (5), (6), and (7). Elementary solutions of the form

$$
\begin{aligned}
& n_{c}(t)=A_{1} e^{\alpha} 1^{t}+A_{2} e^{\alpha_{2} t} \\
& N_{r}(t)=B_{1} e^{\alpha_{1} t}+B_{2} e^{\alpha_{2} t}
\end{aligned}
$$

are assumed.

It is further assumed that the infinite delay time model is adequate so that

$$
\frac{\mathrm{dC}_{\mathrm{i}}}{\mathrm{dt}}=0 \text {. }
$$

The solutions, (24) and (25) are substituted into Equations (5), (6), and (7) and the critical condition, (8) is applied.

Performing the requisite algebra, it is found that the quadratic equation for the decay constants, $\alpha_{1}, \alpha_{2}$, is:

$$
\alpha^{2}+\frac{k_{e f f}^{(b)}}{\ell_{r_{c}^{l}}^{l}}\left[\ell *+\beta \ell_{r}\right]+\frac{k_{e f f}^{(c)}}{\ell_{r_{c}}^{\ell}}=0 .
$$

This quadratic was solved for several cases of the input parameters to discover how the roots varied with these parameters.

COMPUTATIONS OF DECAY CONSTANTS FOR CRITICAL, REFLECTED, TWO-NODE REACTOR MODEL

Several computations were performed to determine the decay constants for various input parameters (see Figures 1 and 2). The input to the code is listed below:

$$
\begin{aligned}
& \mathrm{P} \text { (resonance escape probability in core) } \\
& \mathrm{P}_{C} \text { (core nonthermal leakage probability) } \\
& g_{C} \text { (core nonfast leakage probability) } \\
& P_{r} \text { (reflector return probability) } \\
& l_{R} \text { (lifetime in reflector) } \\
& l_{C} \text { (lifetime in core) } \\
& B \text { (delayed neutron fraction). }
\end{aligned}
$$




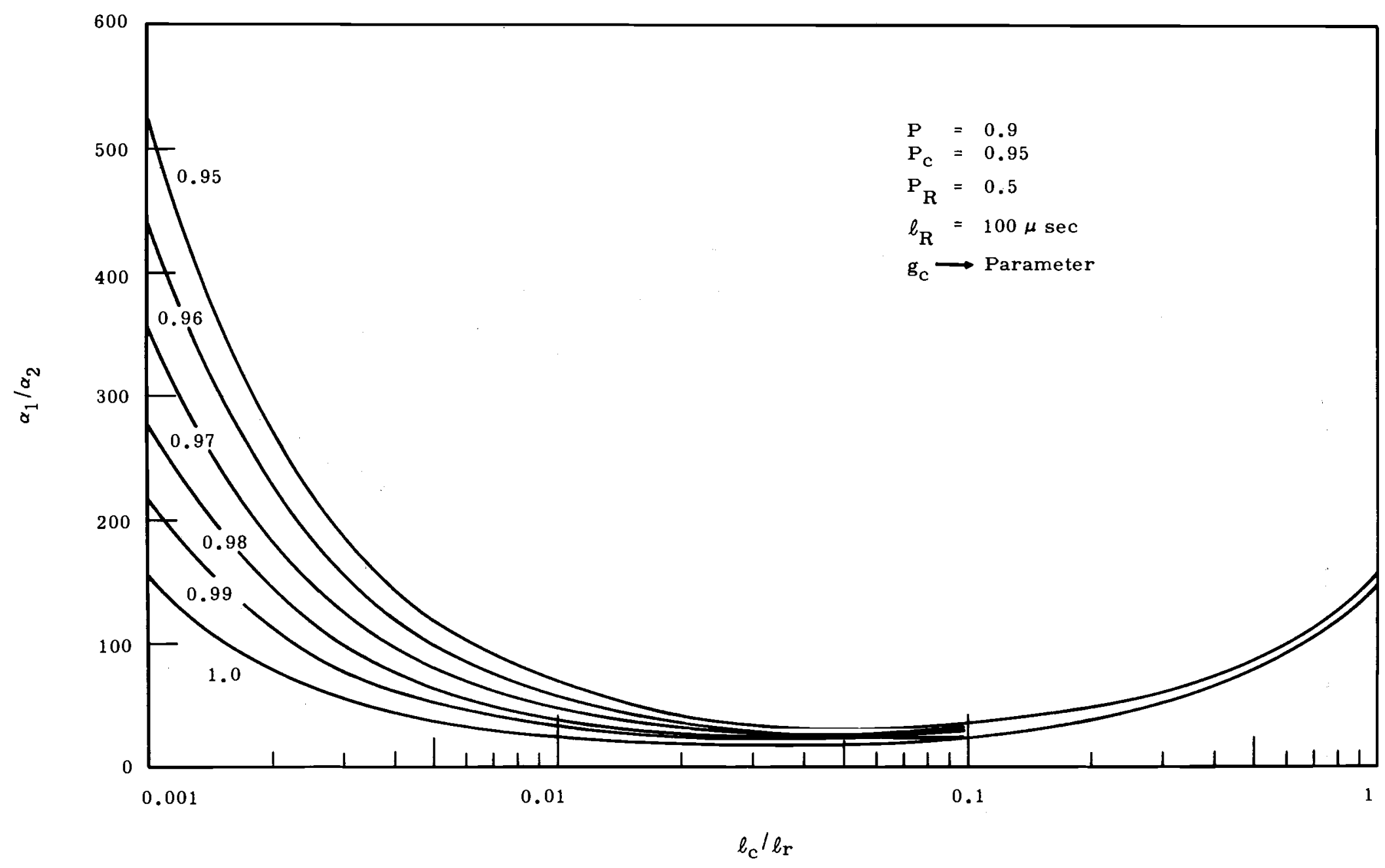

心

FIGURE 1

Variation of Decay Constant Ratio with Core-Reflector Lifetime Ratio with Fast Core NonLeakage Probability as a Parameter 


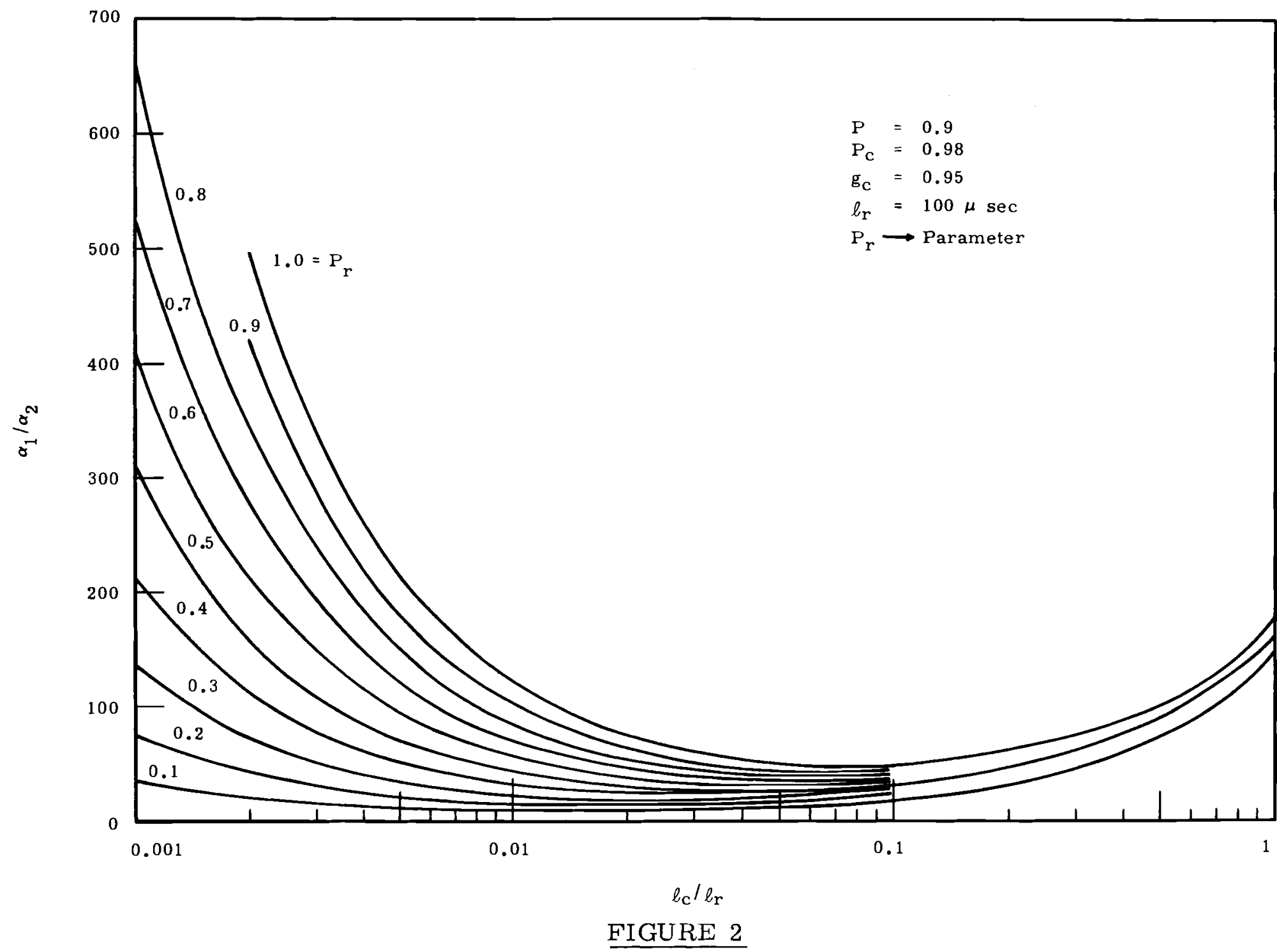

Variation of Decay Constant Ratio with Core-Reflector Lifetime Ratio with Reflector Return Probability as a Parameter 
The program computes the following quantities:

$$
k_{\text {eff }}^{(c)}, k_{\text {eff }}^{(b)}, P_{\text {eff }}, k_{t h}, k_{\infty}, a_{1}, \alpha_{2}, \frac{l_{c}}{l_{R}}, \frac{\alpha_{1}}{\alpha_{2}}, l *, \frac{\beta}{\ell *} .
$$

Several interesting results become apparent upon examining the output of this computation. These are listed below:

(a) If the core and reflector lifetimes differ by less than a factor of ten then the two asymptotic decay constants are insensitive to variations in the coupling parameter linking the core and reflector.

(b) On the other hand, if the core and reflector lifetimes are vastly different (a fast core and a thermal reflector for example) then the decay constants are quite sensitive to a change in coupling.

(c) If the core and reflector lifetimes are quite dissimilar, the ratio of $\alpha_{1} / \alpha_{2}$ increases with increased fast core nonleakage, $g_{c}$.

(d) One very disturbing result was obtained by comparing $\beta / \ell *$ to the asymptotic decay constant, $\alpha_{2}$. In the usual treatment of this problem it is assumed that these two quantities are identical. In this computation, differences as large as $14 \%$ are found and, so far, no systematic way to account for these differences has been discovered. 
INTERNAL DISTRIBUTION

Copy Number

$\begin{aligned} 1 & \text { D. G. Albertson } \\ 2 & \text { C. A. Bennett } \\ 3 & \text { C. L. Bennett } \\ 4 & \text { R. A. Bennett } \\ 5 & \text { S. R. Bierman } \\ 6 & \text { C. L. Brown } \\ 7 & \text { W. W. Brown } \\ 8 & \text { S. H. Bush } \\ 9 & \text { G. J. Busselman } \\ 10 & \text { J. J. Cadwell } \\ 11 & \text { J. L. Carter } \\ 12 & \text { L. L. Carter } \\ 13 & \text { D. E. Christensen } \\ 14 & \text { R. G. Clark } \\ 15 & \text { E. D. Clayton } \\ 16 & \text { R. E. Dahl } \\ 17 & \text { L. C. Davenport } \\ 18 & \text { F. G. Dawson } \\ 19 & \text { D. R. de Halas } \\ 20 & \text { R. F. Dickerson } \\ 21 & \text { B. H. Duane } \\ 22 & \text { M. R. Egan } \\ 23 & \text { G. W. R. Endres } \\ 24 & \text { E. A. Eschbach } \\ 25 & \text { S. L. Fawcett } \\ 26 & \text { J. R. Fishbaugher } \\ 27 & \text { D. G. Foster } \\ 28 & \text { H. A. Fowler } \\ 29 & \text { J. J. Fuquay } \\ 30 & \text { D. W. Glasgow } \\ 31 & \text { C. E. Haines } \\ 32 & \text { R. W. Hardie } \\ 33 & \text { O. K. Harling } \\ 34 & \text { R. A. Harris } \\ 35 & \text { H. Harty } \\ 36 & \text { R. A. Harvey } \\ 37 & \text { C. M. Heeb } \\ 38 & \text { R. E. Heineman } \\ 39 & \text { H. L. Henry } \\ 40 & \text { N. A. Hill } \\ 41 & \text { R. J. Hoch } \\ 42 & \text { P. L. Hofmann } \\ 43 & \text { R. H. Holeman } \\ 44 & \text { R. M. Humes } \\ 45 & \text { U. P. Jenquin } \\ 46 & \text { R. L. Junkins } \\ 47 & \text { E. L. Kelley, Jr. } \\ 48 & \text { D. A. Kottwitz } \\ & \text { H. }\end{aligned}$




\section{INTERNAL DISTRIBUTION}

\section{Copy Number}

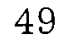

50

51

52

53

54

55

56

57

58

59

60

61

62

63

64

65

66

67

68

69

70

71

72

73

74

75

76

77

78

79

80

81

82

83

84

85

86

87

88

89

90

91

92

93

$94-103$

$104-105$
C. R. Lagergren

D. D. Lanning

J. H. Lauby

B. R. Leonard, Jr.

W. R. Lewis

R. C. Liikala

C. W. Lindenmeier

W. W. Little

R. C. Lloyd

L. L. Maas

D. R. Marr

R. P. Matsen

D. D. Matsumoto

R. E. Nightingale

L. J. Page

H. M. Parker

R. S. Paul

R. E. Peterson

W. A. Reardon

J. J. Regimbal

C. R. Richey

W. C. Roesch

J. T. Russell

J. E. Schlosser

L. C. Schmid

D. R. Skeen

J. D. Smith

R. B. Smith

R. I. Smith

K. B. Stewart

W. P. Stinson

J. J. Stoffels

D. H. Thomsen

T. B. Thornbury

C. R. Tipton, Jr.

V. O. Uotinen

E. E. Voiland

M. T. Walling, Jr.

J. D. White

O. J. Wick

R. D. Widrig

L. D. Williams

J. R. Worden

D. C. Worlton

H. S. Zwibel

Technical Information Files

Technical Publications 


\section{EXTERNAL DISTRIBUTION (Special)}

\section{Number of Copies}

4

1

2

2

24
Argonne National Laboratory

Reactor Physics Constants Center

Atomic Energy Commission, Washington

Attn: Assistant Director for Civilian Reactors, DRD (1)

F. P. Baranowski, Director,

Division of Production (1)

Chief, Physics Branch, DRD (1)

P. B. Hemmig, Physics Branch, DRD (1)

K. G. Kolstad, Assistant Director for Physics and Mathematics Programs (1)

C. D. Luke, Division of Licensing and Regulations (1)

R. H. Odegaarden, Division of Licensing and Regulations (1)

J. L. Schwennesen, Assistant Director, Reactor Products, Division of Production (i)

E. E. Sinclair, Assistant Director for

Advanced Reactor Technology (1)

Water Reactor Branch, DRD (2)

California Institute of Technology

Attn: H. Lurie, Engineering Division

Cornell University, Ithaca, N. Y.

Attn: R. T. Cuykendall, Engineering Physics

R. R. Witson, Physics Department

Duke University, Durham, N.C.

Attn: H. W. Newson, Physics Department

W. J. Seeley, School of Engineering

General Electric Company, Richland, Washington

Attn: T. W. Ambrose

O. F. Beaulieu

E. Z. Block

C. E. Bowers

M. C. Leverett

M. Lewis

L. M. Loeb

D. W. Constable

R. L. Dickeman

G. C. Fullmer

R. O. Gumprecht

M. M. Hendrickson

R. Nilson

G. F. Owsley

R. V. Poe

E. D. Sayre

R. J. Sloat

O. F. Hill

A. E. Smith

H. H. Hopkins

R. E. Tomlinson

R. E. Isaacson

R. E. Trumble

G. R. Kiel 
EXTERNAL DISTRIBUTION (Special) (contd.)

\section{Number of Copies}

1

1

Institute of Atomic Physics

Applied Radioactivity Laboratory

Bucuresti, CP 35, Rumania

Attn: Ing. E. Gaspar

Japan Atomic Energy Research Insitute (JAERI)

Tokai-mura, Naka-gun, Ibaraki-ken, Japan

Attn: Hajime Sakata

Kansas State University, Manhattan, Kansas

Attn: W. R. Kimel, Nuclear Engineering

Manhattan College, Riverdale, New York, N. Y.

Attn: Brother Gabriel Kane

Massachusetts Institute of Technology

Attn: Prof. Irving Kaplan

New York University

Attn: Lyle Borst, Physics Department

North Carolina State College

Attn: R. L. Murray

Purdue University

Attn: P. N. Powers, Nuclear Engineering Department

Richland Operations Office

Attn: M. J. Carrothers

J. M. Musser

J. T. Christy

R. L. Plum

C. D. Compton

R. G. Rader

G. R. Gallager

M. J. Rasmussen

A. T. Gifford

M. R. Schneller

P. G. Holsted

Technical Library

H. A. House

Savannah River Operations Office

Attn: Robert Thorne

Union Carbide Corporation (ORNL)

Attn: C. A. Preskitt

University of Arizona, Tucson, Arizona

Attn: Monte V. Davis, Nuclear Engineering Dept.

University of Florida, Gainesville, Florida

Attn: R. E. Uhrig, Nuclear Engineering

University of Illinois, Urbana, Illinois

Attn: Frederick Seitz, Physics Department

University of Michigan, Ann Arbor, Michigan

Attn: J. H. Gomberg, Nuclear Engineering Dept. 
EXTERNAL DISTRIBUTION (Special) (contd.)

Number of Copies

1

1

1

1

2

1

1

1

1

1
University of Minnesota, Minneapolis, Minnesota Attn: H. S. Isben, Chemical Engineering Department University of Nevada, Reno, Nevada Attn: T. V. Frazier, Physics Department University of Notre Dame, Notre Dame, Indiana Attn: E. W. Jerger, Department of Mechanical Engineering

University of Oregon, Eugene, Oregon Attn: J. L. Powell, Physics Department

University of Tennessee, Knoxville, Tennessee Attn: A. H. Nielsen, Physics Department

P. F. Pasqua, Nuclear Engineering Department

University of Toledo, Toledo, Ohio Attn: J. J. Turin

University of Washington, Seattle, Washington Attn: A. L. Babb, Chemical Engineering Department University of Wisconsin, Madison 6, Wisconsin Attn: M. W. Carbon, Nuclear Engineering Committee Virginia Polytechnic Institute, Blacksburg, Virginia Attn: Andrew Robeson, Physics Department

Washington State University, Pullman, Washington Attn: J. P. Spielman, College of Engineering 
t.

\author{
.
}

